\title{
HYBRID ROCKET MOTOR SCALING PROCESS
}

\author{
A Thesis \\ presented to \\ the Faculty of California Polytechnic State University, \\ San Luis Obispo
}

\author{
In Partial Fulfillment \\ of the Requirements for the Degree \\ Master of Science in Aerospace Engineering
}

by

Joseph B. R. Vanherweg

June 2015 
(C) 2015

Joseph B. R. Vanherweg

ALL RIGHTS RESERVED 


\section{COMMITTEE MEMBERSHIP}

TITLE:

Hybrid Rocket Motor Scaling Process

AUTHOR: Joseph B. R. Vanherweg

DATE SUBMITTED: June 2015

COMMITTEE CHAIR: $\quad$ Dianne DeTurris, PhD

Professor of Aerospace Engineering

COMMITTEE MEMBER: Daniel Walsh, PhD

Professor of Biomedical Engineering

COMMITTEE MEMBER: Eltahry Elghandour, PhD

Lecturer of Aerospace Engineering

COMMITTEE MEMBER: Alexander Athougies, BS

Industry Advisor from Skybox Imaging 


\section{ABSTRACT \\ Hybrid Rocket Motor Scaling Process}

\section{Joseph B. R. Vanherweg}

Hybrid rocket propulsion technology shows promise for the next generation of sounding rockets and small launch vehicles. This paper seeks to provide details on the process of developing hybrid propulsion systems to the academic and amateur rocket communities to assist in future research and development. Scaling hybrid rocket motors for use in sounding rockets has been a challenge due to the inadequacies in traditional boundary layer analysis. Similarity scaling is an amendment to traditional boundary layer analysis which is helpful in removing some of the past scaling challenges. Maintaining geometric similarity, oxidizer and fuel similarity and mass flow rate to port diameter similarity are the most important scaling parameters. Advances in composite technologies have also increased the performance through weight reduction of sounding rockets through and launch vehicles. Technologies such as Composite Overwrapped Pressure Vessels (COPV) for use as fuel and oxidizer tanks on rockets promise great advantages in flight performance and manufacturing cost. A small scale COPV, carbon fiber ablative nozzle and a $\mathrm{N}$ class hybrid rocket motor were developed, manufactured and tested to support the use of these techniques in future sounding rocket development. The COPV exhibited failure within 5\% of the predicted pressure and the scale motor testing was useful in identifying a number of improvements needed for future scaling work. The author learned that small scale testing is an essential step in the process of developing hybrid propulsion systems and that ablative nozzle manufacturing techniques are difficult to develop. This project has primarily provided a framework for others to build upon in the quest for a method to easily develop hybrid propulsion systems sounding rockets and launch vehicles. 


\section{TABLE OF CONTENTS}

LIST OF TABLES ........................................................................................ vii

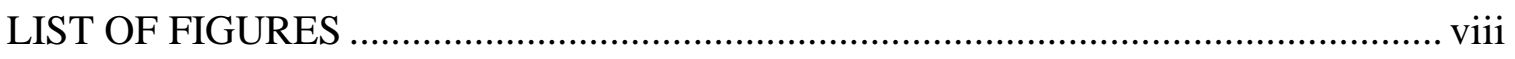

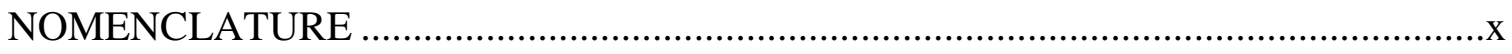

CHAPTER

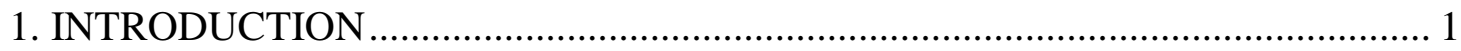

1.1. Hybrid Rocket Background .................................................................... 2

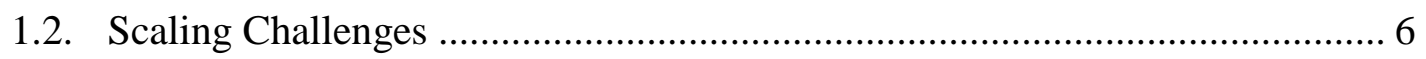

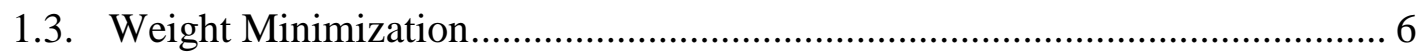

2. SIMILARITY SCALING LITERATURE REVIEW ……………....................... 8

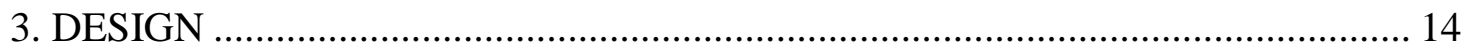

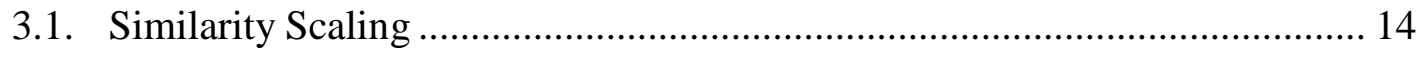

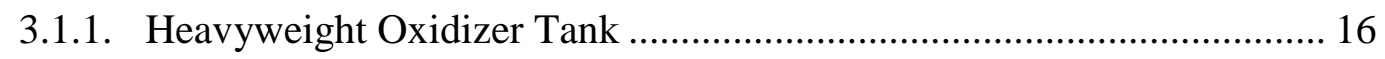

3.1.2. Combustion Chamber............................................................................ 17

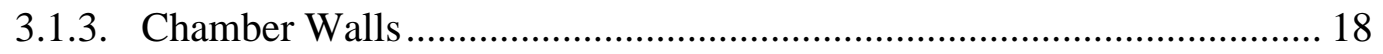

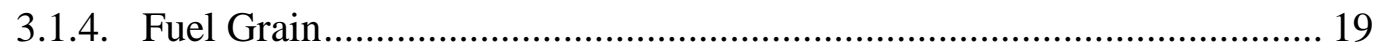

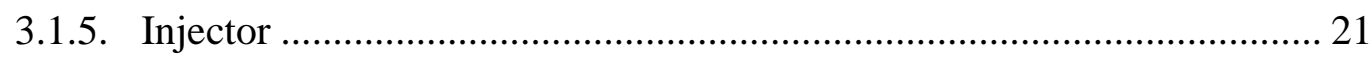

3.1.6. Nozzle Design ................................................................................. 23

3.2. Weight Minimization by Utilizing a COPV .................................................. 26

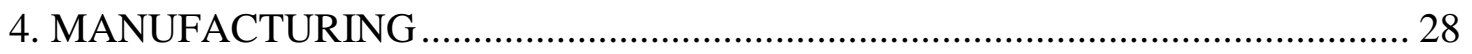

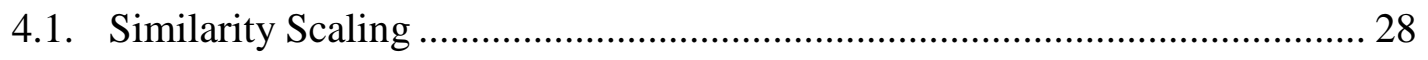

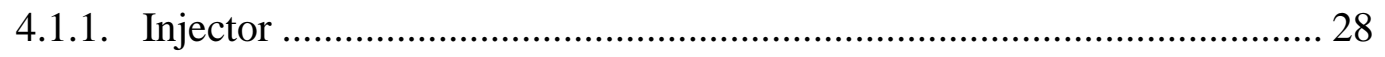

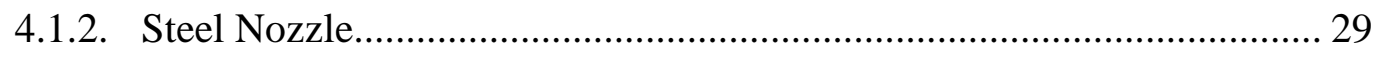

4.2. Weight Minimization by Utilizing a Phenolic Nozzle ..................................... 30

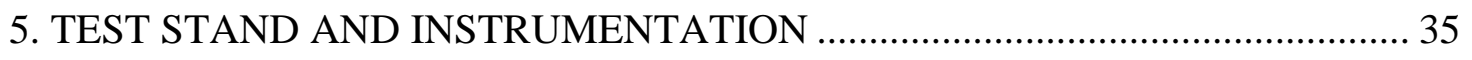

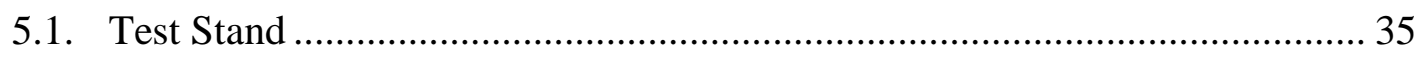

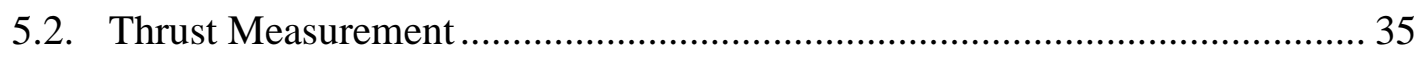

5.3. Oxidizer Tank Load Cell .......................................................................... 36

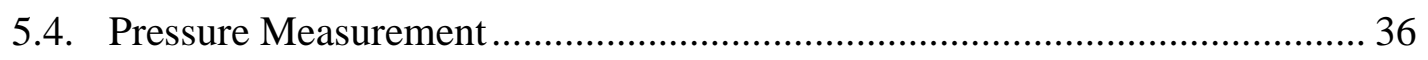

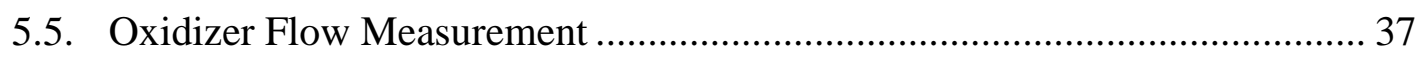

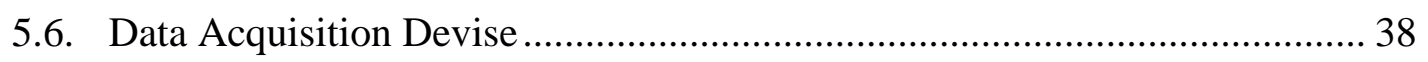

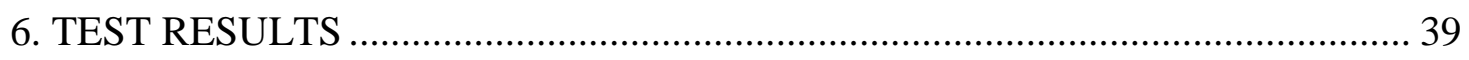

6.1. Similarity Scaling Small Scale Test Fire ........................................................ 39 
6.2. COPV Weight Minimization Testing .................................................... 45

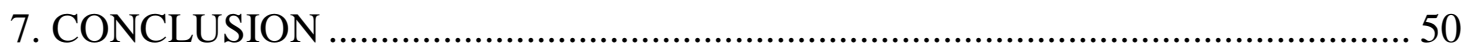

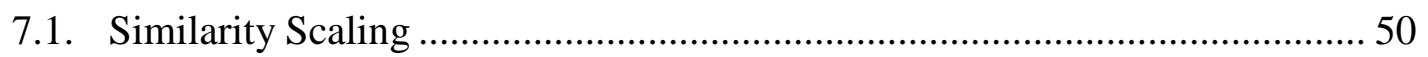

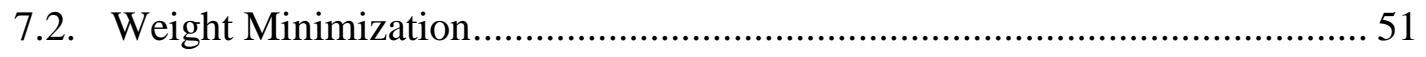

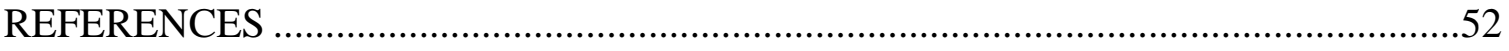

APPENDICES

A. HaRMleSS Static Test Fire Procedures ............................................................... 53

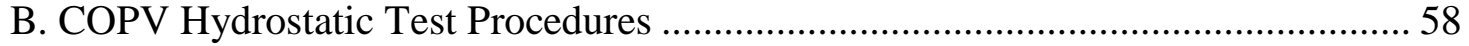

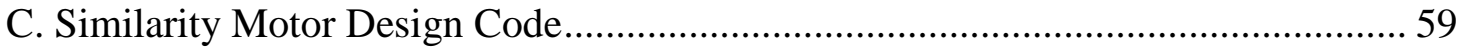




\section{LIST OF TABLES}

Table

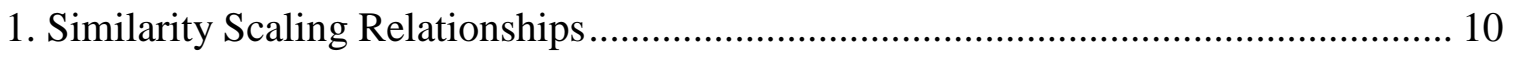

2. Expected Relationships in Similarity Scaling .................................................. 10

3. Summary of Full Scale Versus Small Scale Motor Parameters ................................. 15

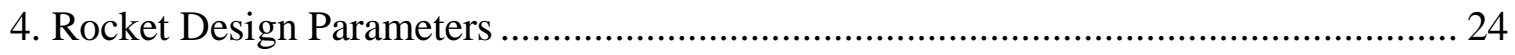

5. Carbon Fiber Phenolic Laminate Tensile Test Results ............................................ 30

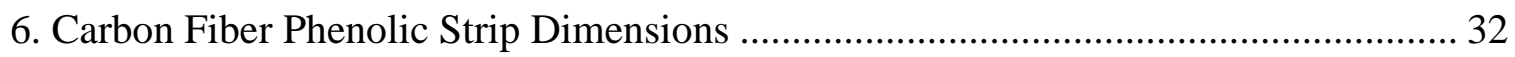

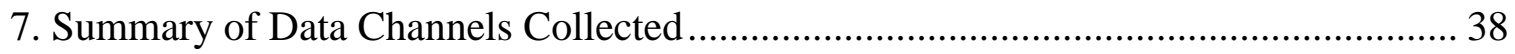

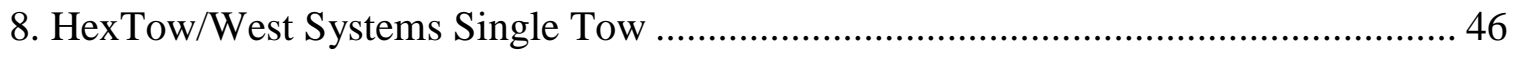

9. HexTow IM2A Properties Comparison .................................................................... 46

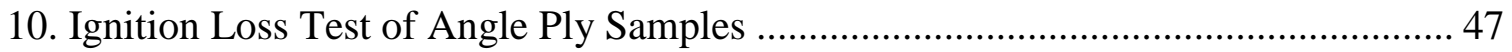

11. Angle Play Tensile Sample Volume Fraction................................................... 47

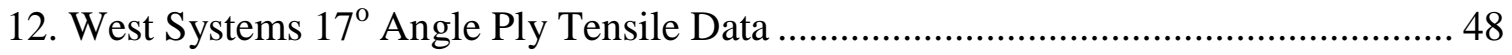

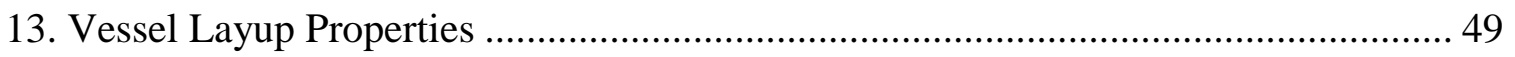




\section{LIST OF FIGURES}

Figure $\quad$ Page

1. Basic Elements of a Hybrid Powered Sounding Rocket ${ }^{1}$......................................... 3

2. Hybrid Rocket Combustion Chamber Layout ${ }^{1}$.......................................................... 4

3. Diagram of Boundary Layer Combustion................................................................ 5

4. An Illustration of a Flame Boundary Layer in a Typical Hybrid Rocket Motor $^{2} \ldots \ldots . . . . .8$

5. Regression Rate Formulas Examined by Estey et al. ${ }^{2}$............................................. 9

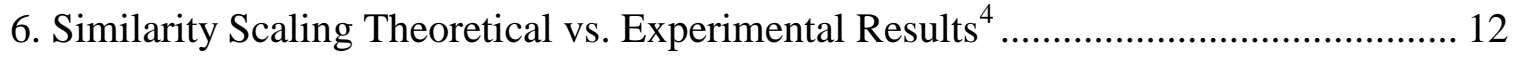

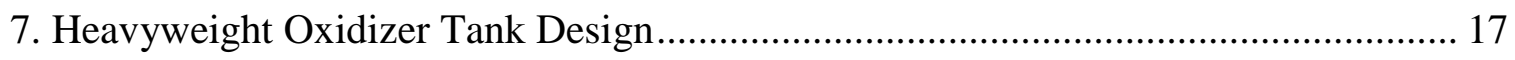

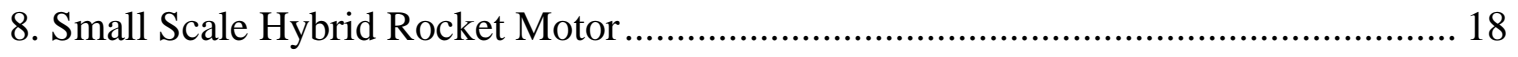

9. Heavyweight Combustion Chamber .......................................................................... 19

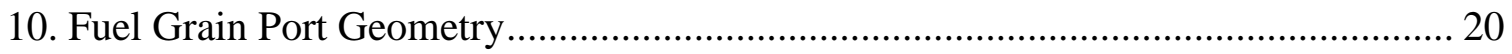

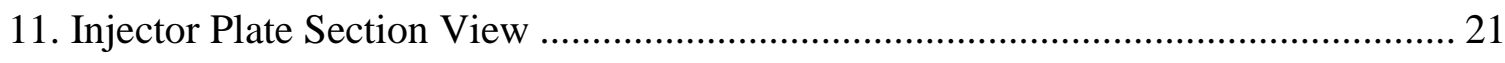

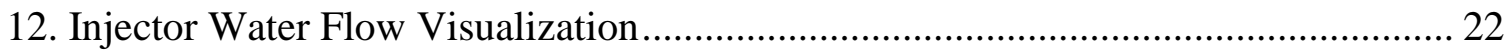

13. CFD Model of Oxidizer Flowing Through Combustion Chamber........................... 22

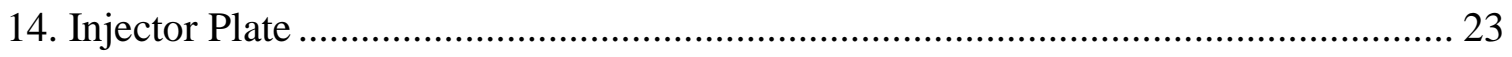

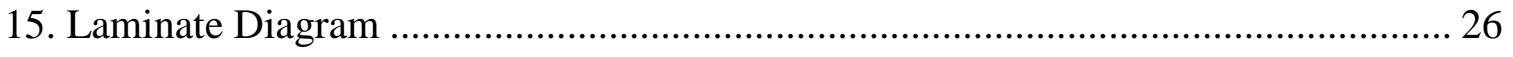

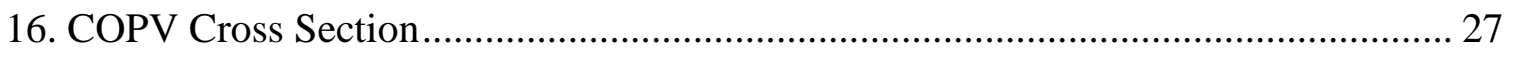

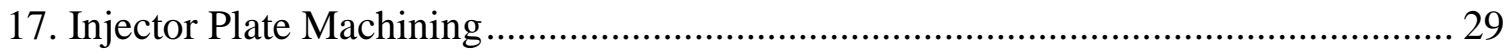

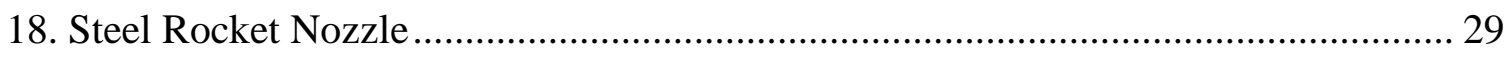

19. Carbon Fiber Phenolic Nozzle ........................................................................... 31

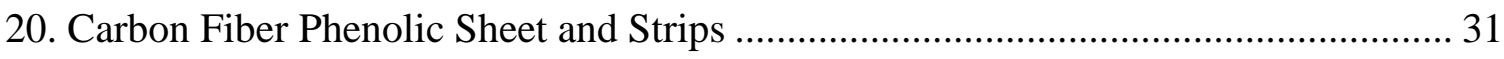

21. Carbon Fiber Phenolic Nozzle Layup Process ..................................................... 33

22. Carbon Fiber Phenolic Nozzle Machining .............................................................. 34 
23. Carbon Fiber Phenolic Nozzle Converging Section ............................................ 34

24. Small Scale Hybrid Rocket Motor on Test Stand .................................................... 35

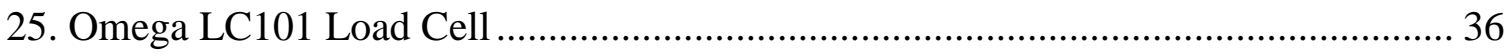

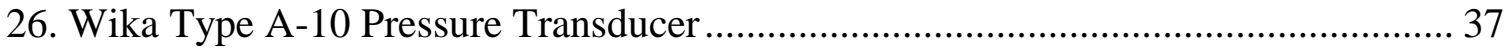

27. Chamber Pressure Port................................................................................... 37

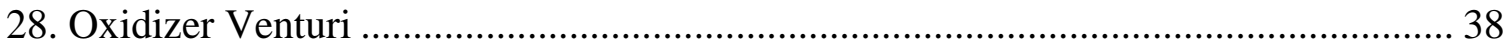

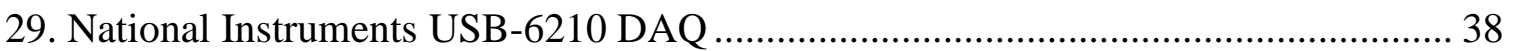

30. Small Scale Hybrid Rocket Motor on the Test Stand ........................................... 39

31. Small Scale Hybrid Rocket Motor Thrust Measurement....................................... 41

32. Small Scale Hybrid Rocket Motor Pressure Measurement..................................... 42

33. Small Scale Hybrid Rocket Motor Oxidizer Tank Measurement ............................. 42

34. Small Scale Hybrid Rocket Motor Oxidizer Flow Measurement ............................ 42

35. Small Scale Hybrid Rocket Motor Steel Nozzle After Test Fire............................. 43

36. Small Scale Hybrid Rocket Motor Injector after Test Fire .................................... 44

37. Small Scale Hybrid Rocket Motor Inner Fuel Grain after Test Fire......................... 44

38. Small Scale Hybrid Rocket Motor Outer Fuel Grain after Test Fire ........................ 45

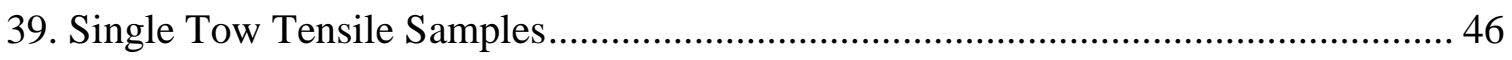

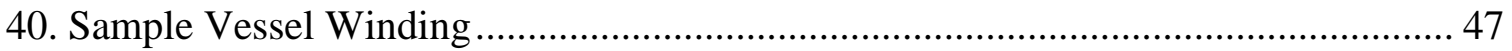

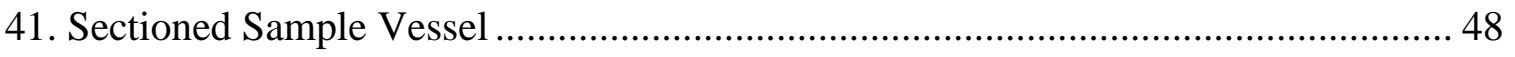

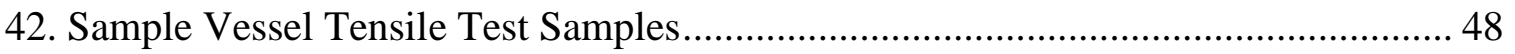

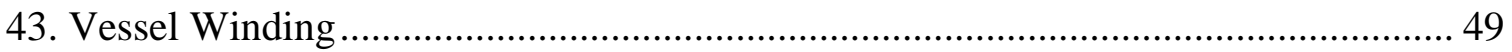

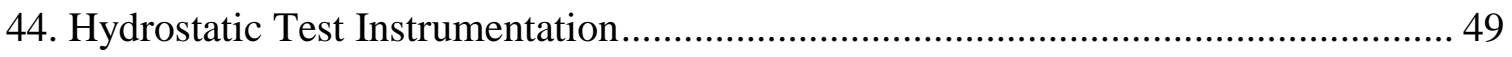

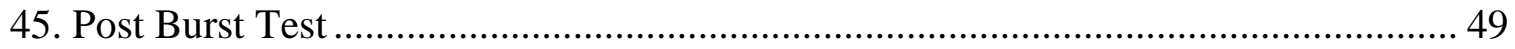


NOMENCLATURE

\begin{tabular}{|c|c|c|c|}
\hline \multicolumn{4}{|c|}{ Nomenclature } \\
\hline A & area & $\mathrm{t}$ & time \\
\hline $\mathrm{a}$ & empirical coefficient & $\mathrm{u}$ & axial velocity \\
\hline $\mathrm{C}_{\mathrm{d}}$ & flow coefficient & $\alpha$ & angle \\
\hline $\mathrm{D}$ & port diameter & $\mu$ & viscosity \\
\hline$f$ & fuel & $\rho$ & density \\
\hline $\mathrm{G}$ & oxidizer mass flux & $\sigma$ & stress \\
\hline g & standard gravity acceleration & \multirow{2}{*}{\multicolumn{2}{|c|}{ Subscripts }} \\
\hline $\mathrm{I}_{\mathrm{sp}}$ & specific impulse & & \\
\hline $\mathrm{L}$ & fuel grain length & $\mathrm{b}$ & burning \\
\hline$\dot{\mathrm{m}}$ & mass flow rate & $\mathrm{c}$ & chamber \\
\hline $\mathrm{N}$ & number of & e & nozzle exit \\
\hline $\mathrm{n}$ & empirical exponent & $\mathrm{f}$ & flame; fuel \\
\hline $\mathrm{O} / \mathrm{F}$ & oxidizer to fuel (mass) ratio & $\mathrm{i}$ & initial \\
\hline $\mathrm{p}$ & pressure & inj & injector \\
\hline $\operatorname{Re}$ & Reynolds number & o & oxidizer \\
\hline $\mathrm{r}$ & radius & $\mathrm{p}$ & port \\
\hline$\dot{\mathrm{r}}$ & linear regression rate & $\mathrm{s}$ & solid \\
\hline$S$ & load & $\mathrm{x}$ & principle direction \\
\hline $\mathrm{T}$ & temperature & $\mathrm{y}$ & $\begin{array}{l}90^{\circ} \text { to principle } \\
\text { direction }\end{array}$ \\
\hline
\end{tabular}




\section{INTRODUCTION}

Hybrid rocket motor technology has been of cyclical interest in the aerospace field for many years and more recently hybrid motors have been used in Space Ship 2 and Dream Chaser spacecraft. Scaling such motors has been a challenge because the process is not well understood. In order to utilize a small scale model to assist in the development of a full scale hybrid rocket motor, techniques such as similarity parameters are useful. Similarity parameters can be used to predict at which input values two scales of similarly designed hybrid motors will perform with the same efficiency. The two "similar" motors should function with the same dominant internal kinetics of combustion in order to obtain "similarity." This project seeks to demonstrate a method for successfully developing an inexpensive hybrid rocket motor propulsion system for a sounding rocket. This methodology can be applied to a variety of launch vehicle or sounding rocket applications. Topics such as similarity scaling, weight optimization, component design and manufacturing, and testing apparatus will be discussed.

The specific hybrid motor configuration which will be covered in this work is a pressure fed hybrid rocket motor with a coaxial grain configuration. The oxidizer and fuel used for testing in the motor are liquid Nitrous Oxide $\left(\mathrm{N}_{2} \mathrm{O}\right)$ and Hydroxl-Terminated Polybutadeine (HTPB), respectively. Building a small scale motor is a good way to expose design issues before investing in a full scale motor development program. This project utilized an incremental motor scaling procedure to take advantage of the benefits of a small scale test platform before full scale development. The small scale $\mathrm{N}$ class motor allows for gathering of data used in designing the full scale $\mathrm{R}$ class motor. In order to develop a successfully scaled hybrid rocket the two motors need to be designed in the 
proper configuration. If the scaling is successful, the full scale motor configuration will function as expected and have a short development schedule.

The technology for creating simple and lightweight hybrid rocket motor structures is a developing field. Composite technology is expanding to dominate the landscape of rocket structures. Advances in composite manufacturing techniques such as thermoplastic matrix composites and out-of-autoclave curing offer the potential for lower cost and higher performance structures for the next generation of launch vehicles.

\subsection{Hybrid Rocket Background}

A rudimentary hybrid motor powered sounding rocket or launch vehicle the (Figure 1) would generally hold the payload and possibly recovery systems in the nose section of the rocket. There are several reasons for the placement of the payload in the nose of the rocket. First, the propulsion system is most easily placed in the rear of the rocket away from the nose so placing a payload in that space does not interfere with the engine or motor. This is especially true when the rocket has multiple stacked stages. Second, placing weight in the nose causes the center of mass of the rocket to be more forward. Having the center of gravity (CG, the point where gravitational forces act on the rocket body) more forward than the center of pressure $(\mathrm{CP}$, the point where aerodynamic forces act on the rocket body) causes the forward flight of the rocket to be stable. If the $\mathrm{CG}$ is less than one rocket diameter in front of the $\mathrm{CP}$ forward flight will not be stable and the rocket will fly erratically and probably break up unless is has an active stability system. This passive technique of having the CG over one body diameter in front of the $\mathrm{CP}$ is what all hobby rockets utilize for flight stability. Third, the payloads on rockets 
may need to be able to have a forward view for scientific or orientation purposes so having anything in front of them would diminish the usefulness of the mission.

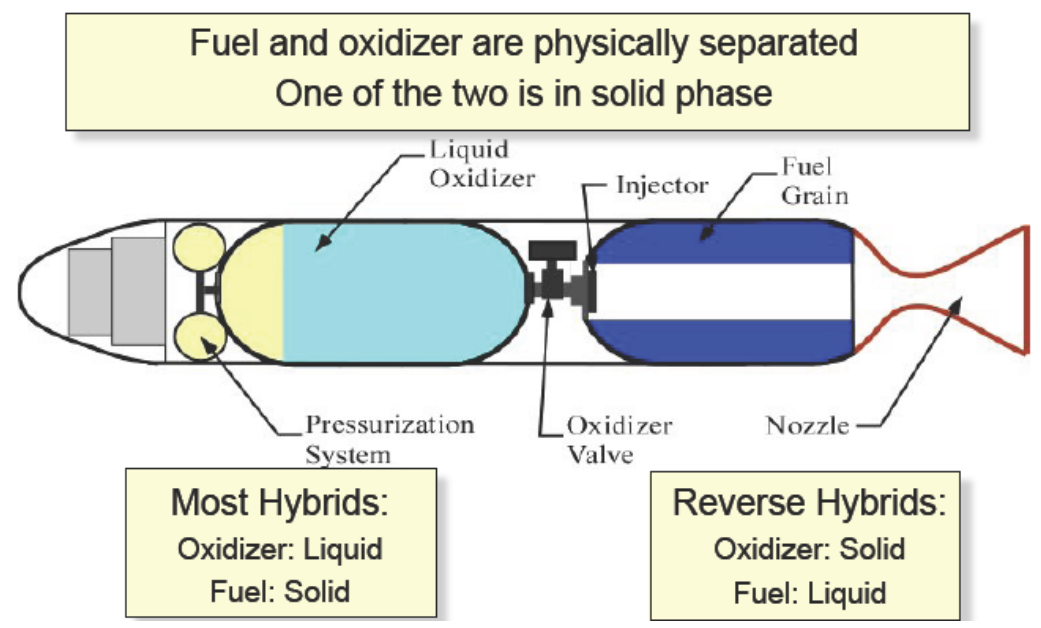

Figure 1. Basic Elements of a Hybrid Powered Sounding Rocket ${ }^{1}$

The next system in a rudimentary hybrid powered sounding rocket would be the propulsion system, starting with the liquid oxidizer pressurent tanks. The liquid oxidizer used in most hybrids must be forced into the combustion chamber in some way. Two options for getting the oxidizer into the combustion chamber are a pressurized gas or pumps. Pumps are widely used for forcing both the liquid oxidizer and liquid fuel into the combustion chamber of bi-propellant rocket engines. The cost of developing and manufacturing the turbopumps used in most launch vehicles is the most significant single cost in the creation of those vehicles. This is why pressure fed systems are used more readily in low cost vehicles like sounding rockets. A pressure fed oxidizer feed system for a hybrid rocket consists of pressurent tanks feeding into the oxidizer tank through a regulator and forcing the liquid oxidizer through the injector once the oxidizer valve is 
open. The oxidizer then sprays onto the solid fuel in the combustion chamber and combustion occurs, forcing hot gas out of the nozzle which produces thrust.

Hybrid rocket combustion in a simple circular combustion port occurs in what is known as the turbulent boundary layer diffusion flame zone. The combustion zone is denoted by the red line in Figure 2. There are many different oxidizer and fuel combinations which can be used in a hybrid rocket motor but in a traditional hybrid the liquid oxidizer is sprayed into the top of the combustion chamber though an injector plate and onto the solid fuel.

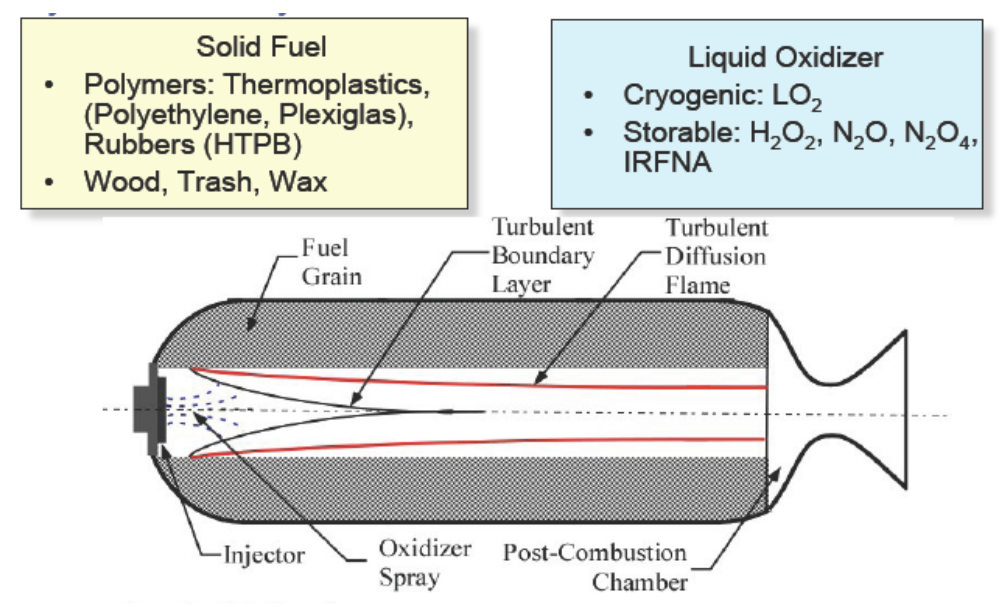

Figure 2. Hybrid Rocket Combustion Chamber Layout ${ }^{1}$

If sufficient heat is available in the chamber when the oxidizer is sprayed into the combustion chamber the oxidizer will mix with the fuel and ignite. The oxidizer is flowing from the injector but the fuel is sublimating from the surface of the solid fuel grain because of the heat of combustion. In between the oxidizer and fuel sources are concentration, temperature, and velocity gradients (Figure 3). The concentration of both the fuel and oxidizer decreases as they near the flame zone. Inversely, the temperature 
increases when approaching the flame zone while the axial velocity increases closer to the center of the port.

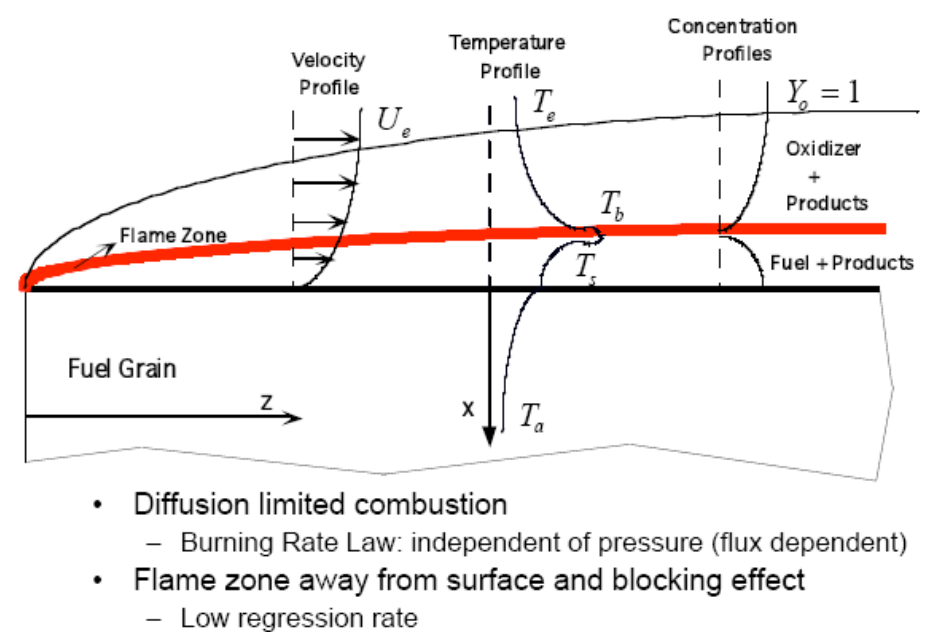

\section{Figure 3. Diagram of Boundary Layer Combustion ${ }^{1}$}

Due to how combustion occurs, the location of the flame zone is dependent on the flux of fuel sublimating from the fuel grain. When the flame zone is closer to the fuel grain the fuel regression rate increases. However, when regression rate increases the flame zone moves away from the fuel grain which constantly balances the location of the flame zone based on the amount of energy reaching the fuel grain and the flux of fuel coming from the grain. One of the challenges of utilizing hybrids for industrial applications is that they produce low thrust for their volume compared to liquid or solid rocket propulsion systems. This limitation comes from the fact that thrust is tied to the regression rate and surface area of the fuel grain. Overcoming the low regression rate problem would dramatically increase the usefulness of hybrids in sounding rockets and launch vehicles. 


\subsection{Scaling Challenges}

Historically there have been many challenges in the process of developing and scaling hybrid rocket motors for sounding rocket and launch vehicle applications. Hybrid rockets have not had as much attention as either liquid or solid fuel propulsion systems in the research community. The fact that hybrid rocket combustion kinetics are more complex to model than those in liquid or solid combustors, leaves hybrid rocket technology in too immature of a state to be widely used by industry. Several organizations, including American Rocket Company (AMROC), have done research on scaling hybrid rockets for launch vehicles. Unfortunately scaling of hybrid rocket motors still proves to be a difficult task and is not considered one of the most cost effective propulsion solutions for launch vehicles. Even Sierra Nevada's dream chaser vehicle has at this point in time switched from the hybrid propulsion system that was originally under development for a more conventional liquid rocket propulsion system.

\subsection{Weight Minimization}

The mass fraction of a rocket's propulsion system can be one of the most significant factors in the flight performance of the rocket. It is especially critical to optimize the mass fraction of a rocket when seeking a single stage to orbit (SSTO) launch vehicle. It is important to have the lowest mass fraction possible while maintaining appropriate Factors-of-Safety (FoS). Therefore the lightest weight structures are ideal because they minimize the amount of overhead weight that a rocket must carry into space. Metallic monocoque structures are typical in most rockets, especially in the propellant tanks. However, composites have found use in the fairings and other structural elements of launch vehicles. Advances in composite technology have allowed for research into composite overwrapped pressure vessels (COPV) as propellant tanks for the 
next generation of launch vehicles. A COPV can either be a composite shell wrapped over a metallic or polymer liner or just a composite shell. The shape of a COPV also has a number of possibilities; although a cylinder with hemispherical end caps is very common, for rocket structures. Composite manufacturing has a high potential to revolutionize launch vehicle structural design due to the advances in COPV technology. 


\section{SIMILARITY SCALING LITERATURE REVIEW}

During the 20th century there was extensive research on chemical rocket propulsion. Both liquid and solid propulsion systems received a lot of attention while hybrid rocketry was focused on to a lesser degree. The work done with hybrid rocket motors utilized empirical solid fuel regression rate models and boundary layer analysis of combustion within the motor (Figure 4). It was found that these models had very poor correlation when scaling the rocket motor or when changing the combustor configuration.

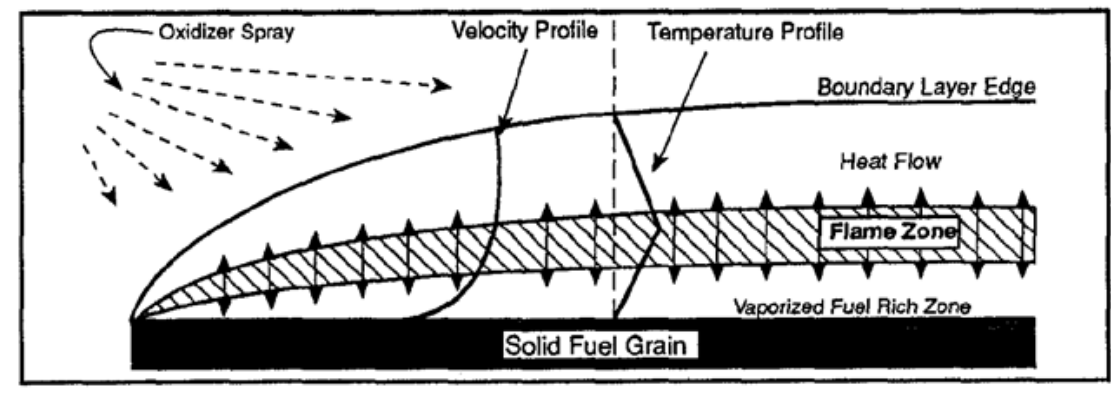

Figure 4. An Illustration of the Flame Boundary Layer in a Typical Hybrid Rocket Motor ${ }^{2}$

In 1991 Estey et al. published a study [2] which examined various empirical formulas based on boundary layer analysis to predict the regression rate as applied to scaling. The research utilized hybrid motor data from testing which AMROC had conducted. It was noted that the empirical formulas were adequate when used on the same scale of motor for which they were developed but were inadequate for scaling to significantly larger motors. As seen in Figure 5 the average extrapolation error could be quite significant for the regression rate equations, especially the more complex regression equations which took into account more terms. The trend of deviating from the regression equations when scaling hybrid rocket motors posed a significant challenge to the industry for developing large scale hybrid motors for launch vehicles. It became obvious that a more predictable model for scaling was needed. 
Results of Extrapolation of the Small Scale Motor Analysis to Large Scale for the AMROC Motors

\begin{tabular}{|c|c|c|c|c|c|c|}
\hline Syatem & Equation & $\mathbf{A}$ & $\mathrm{n}$ & $\mathrm{m}$ & $\begin{array}{c}\text { Average } \\
\text { Error }{ }^{1} \\
(\%) \\
\end{array}$ & $\begin{array}{c}\text { Average } \\
\text { Extrapolation } \\
\text { Error }{ }^{2}(\%)\end{array}$ \\
\hline 1 & $\dot{r}=\mathrm{A} \mathrm{G}^{0.8} \mathrm{~L}^{-0.2}$ & 0.20 & 0.8 & -0.2 & 2.9 & 13.6 \\
\hline 2 & $\dot{r}=A G G^{m}$ & 0.19 & 0.79 & .0 .18 & 2.8 & 11.1 \\
\hline 3 & $\dot{\mathbf{r}}=\mathbf{A} G_{0}^{n} L^{m}$ & 0.07 & 0.62 & 0.11 & 4.1 & 49.5 \\
\hline 4 & $\dot{r}=A G_{0}^{m} L^{m}\left(1+\frac{2 A_{4} n \rho L^{(1+m)}}{D G_{0}^{(1-n)}}\right)$ & 0.11 & 0.69 & .0 .02 & 3.9 & 21.9 \\
\hline 5 & $\dot{r}=A G^{0.8}$ & 0.094 & 0.8 & & 4.4 & 10.5 \\
\hline 6 & $\dot{r}=\mathbf{A} G^{\mathbf{n}}$ & 0.089 & 0.70 & & 4.5 & 17.9 \\
\hline 7 & $\dot{r}=\mathbf{A G}_{0}^{\mathrm{n}}$ & 0.11 & 0.65 & & 5.0 & 28.3 \\
\hline 8 & $\dot{\mathbf{r}}=\mathbf{A} \mathrm{G}_{0}^{\mathrm{m}} \mathrm{L}^{\mathrm{m}}\left(1-\mathrm{e}^{-\mathrm{P} / \mathrm{P}_{\mathrm{r} \alpha}}\right)$ & 0.07 & 0.62 & 0.11 & 4.1 & 49.5 \\
\hline 9 & $\dot{\mathrm{r}}=\mathrm{AG}_{0} \mathrm{~L}^{\mathrm{m}}\left(1-\mathrm{e}^{-\mathrm{D} / \mathrm{D}_{r \alpha}}\right)\left(1-\mathrm{e}^{\left.-\mathrm{P} / \mathbf{P}_{r \alpha}\right)}\right.$ & 0.083 & 0.59 & 0.1 & 4.2 & 73.8 \\
\hline
\end{tabular}

\footnotetext{
Data includes a total of 12 small scale motors $(D=1.5 \mathrm{in})$ and 6 large scale motors $\left(\mathrm{D}_{\mathrm{h}}=5.5-10.5 \mathrm{in}\right)$ $P_{\text {ref }}=1 \mathrm{psi}$

$D_{\text {ref }}=1.0$ inch

Notes:

1. Average error when the equation is applied to the small scale motors $\left(D_{h}=1.5\right.$ in)

2. Average error when the equation is compared with measurements from the larger scale motors $\left(D_{\mathrm{h}}=5.5-10.5\right.$ inches)
}

Figure 5. Regression Rate Formulas Examined by Estey et al. ${ }^{2}$

In January of 1996 Merkle and Venkateswaran published a paper [3] discussing the use of Computational Fluid Dynamic (CFD) analyses of the Navier-Stokes equations coupled with solid-phase pyrolysis, gas-phase combustion, turbulence, and radiation analysis to study hybrid rocket combustor flow fields for use in scaling hybrid rocket motors. The analysis was able to accurately predict the trend in lower regression rates as port diameter increased, which was a weakness of traditional boundary layer analysis. The analysis technique, while effective, was quite involved and did not provide a simple explanation for the decreasing regression rate trend in the increasing test motor size which was tested to confirm the analysis technique. The explanation provided in the paper dealt with relative flame layer distance to the fuel and relative contribution between the convective and radiative heat flux to the fuel grain as it varied with size scale-up. The radiative heat flux contribution was expected to grow due to a surface area-to-volume relationship of radiation absorber versus radiation production. 
Merkle and Venkateswaran's work was successful in modeling the behavior of hybrid rockets in scaling. However, in July of 1996 Gany published a paper [4] which outlined what he called similarity scaling parameters for use with boundary layer analysis which achieved the same objective. These similarity parameters (Table 1) were an analytical approach to the scaling problem for use with boundary layer analysis which is easier to conduct than a full CFD based solution. If the six primary similarity requirements are met in the design then two hybrid motors are expected to exhibit a predictable regression rate and a constant specific impulse during scaling (Table 2), in which the first three are the most critical.

Table 1. Similarity Scaling Relationships

\begin{tabular}{|ll|}
\hline$\#$ & Similarity Requirements \\
\hline 1 & $\mathrm{~L} \alpha \mathrm{D}$ \\
\hline 2 & $\mathrm{O} / \mathrm{F}$ \\
\hline 3 & $\dot{\mathrm{m}} \alpha \mathrm{D}$ \\
\hline 4 & $\mathrm{Re}=\rho^{*} \mathrm{u}^{*} \mathrm{D} / \mu$ \\
\hline 5 & $\mathrm{p} \alpha 1 / \mathrm{D}$ \\
\hline 6 & $\mathrm{t}_{\mathrm{b}} \alpha \mathrm{D}^{2}$ \\
\hline
\end{tabular}

Table 2. Expected Relationships in Similarity Scaling

\begin{tabular}{|ll|}
\hline$\#$ & Similarity Predictions \\
\hline 1 & $\dot{\mathrm{r}} \alpha 1 / \mathrm{D}$ \\
\hline 2 & $\mathrm{I}_{\mathrm{sp}}=$ const. \\
\hline
\end{tabular}

Similarity conditions are the running conditions for two scales of similarly designed hybrid motors at which the internal kinetics of combustion operate in the same manner. Gany ${ }^{3}$ set forth partial scaling factors which are useful to consider for scaling since full similarity is not always possible or necessary. These factors, when used properly, should ensure that similar performance is achieved at both large and small scale 
hybrid motors used in a propulsion system development program without the need for a complex CFD suite. The first similarity requirement is for the length (L) to diameter (D) ratio of both the small scale and large scale motors to be the same. The second requirement is for the same oxidizer $(\mathrm{O})$ and fuel $(\mathrm{F})$ to be used in both the small and large scale motors as well as the same oxidizer to fuel ratio. The third requirement is for the mass flow rate $(\dot{\mathrm{m}})$ to combustor diameter ratio to be the same in both the small and large scale motors. The last three requirements can be deviated from to accommodate design concerns but the deviation must be accounted for. The forth requirement is that both the large scale and small scale motors have the same Reynolds number $(\mathrm{Re})$ profile throughout the combustion chamber during the burn. The fifth requirement is for the chamber pressure (p) to scale inversely with chamber diameter. The sixth requirement is for the burn time $\left(t_{b}\right)$ to scale with chamber diameter squared $\left(D^{2}\right)$. Further details on the similarity scaling parameters can be found in Gany's paper titled "Scale Effects in Hybrid Motors under Similarity Conditions ${ }^{4}$." Gany did a number of experiments to confirm his conclusions and the hybrid motor performance data gathered did correlate with the predicted outcomes of the similarity scaling parameters (Figure 6). 


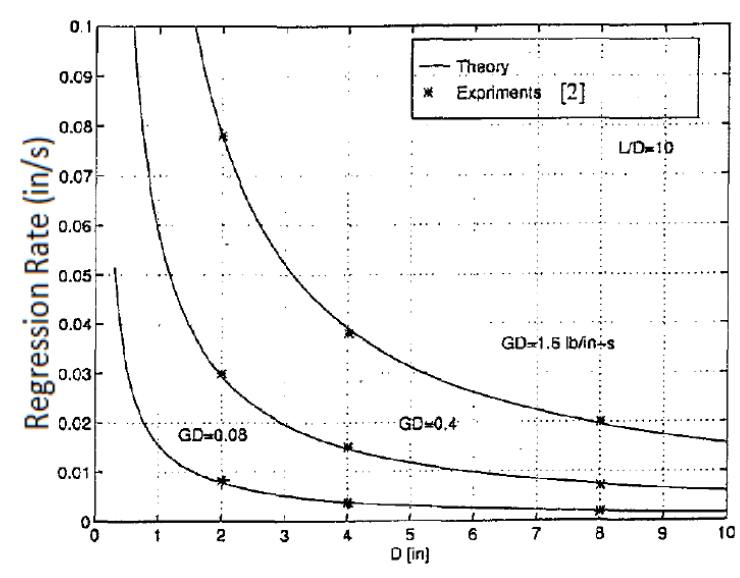

$\dot{\mathrm{r}}$ vs $\mathrm{D}$ for hybrid motors maintaining similarity of operating conditions. Comparison between present theory and test results of Ref. 2 on GOX+PMM systems at different GD levels.

A)

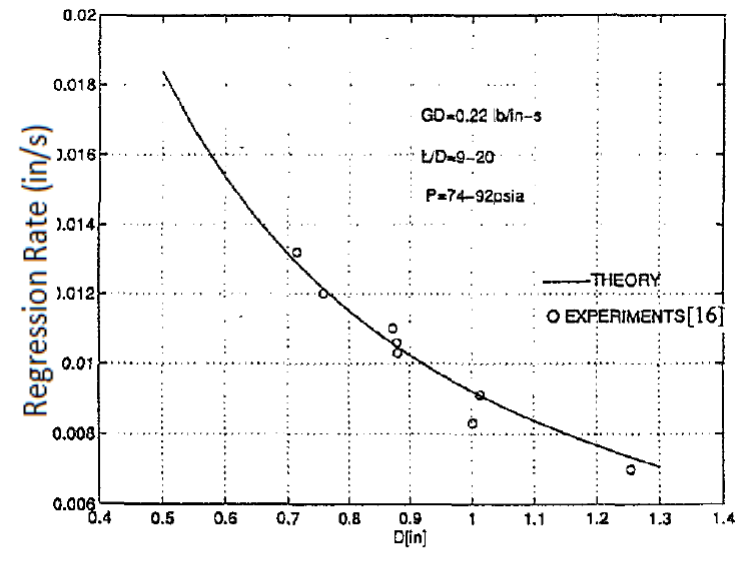

$\dot{\mathrm{r}}$ vs $\mathrm{D}$ for hybrid motors scaled under similarity conditions. Comparison between present theory and test results of Ref. 16 for liquid $\mathrm{H}_{2} \mathrm{O}+\mathrm{PE}$ system.

Figure 6. Similarity Scaling Theoretical vs. Experimental Results ${ }^{4}$

In 2003 Swami and Gany followed up on Gany's work [5] and examined the trends in regression rate with scaling at different oxidizer mass flux values. The goal of this work was to identify the most critical similarity parameters in the scaling process. The parameters which were identified as most critical were: (1) maintaining geometric similarity, (2) using same oxidizer and fuel combination, (3) scaling $\dot{\mathrm{m}}_{\mathrm{ox}}$ in proportion to D (resulting in $G^{*} D=$ const). Their work also supported the similarity scaling analysis and provided further test data to support the similarity scaling process. However, no motor with a port diameter larger than 1.75 inches was tested.

In 2013 Cai et al. [6] utilized Gany's similarity scaling work in the development of a numerical pipe turbulent boundary combustion theory model combined with turbulence, combustion, solid fuel pyrolysis and solid-gas coupling. Cai et al. used the model to analyze data from test fires conducted at Pennsylvania State University and found that the solid fuel regression rate trends from the tests matched the trends predicted by the model. Cai et al. concluded that the trend of decreasing regression rate with 
increasing port diameter can be significant in motors which have a large variation in port diameter throughout the burn.

Also in 2013 Shan et al. [7] used the similarity parameters in a hybrid rocket motor code for the simulation of N2O/HTPB hybrid rocket motor operation and scale effect analysis. The code operated by solving the unsteady Navier-Stokes equations using a corrected compressible difference scheme and a two-step, five species combustion model. The results of Shan et al.'s work was similar to Cai et al.'s but Shan et al. offered a preliminary explanation for the decrease in fuel regression rate when scaling lab-scale hybrid rocket motors to larger motors. Shan et al.'s explanation was that "greater distance from fuel surface to high temperature region of the flow field lowers the fuel regression." ${ }^{6}$ While this explanation is not new or profound since it is similar to the explanation which Merkle and Venkateswaran gave in their work, it does illuminate the phenomena which are influenced during the similarity scaling process. The "r $\alpha 1 / \mathrm{D}$ " similarity prediction describes the effect on regression rate based on the change in distance between the fuel surface and the flame front depending on the port diameter.

Both Cai et al.'s and Shan at al.'s work further supported the effectiveness and usefulness of similarity scaling parameters in hybrid rocket motor design. At this time no further work has been found which utilizes similarity scaling parameters for analysis or for a practical scaling application. 


\section{DESIGN}

To form the basis of this project information from literature and past work on hybrid rocket motors at California Polytechnic State University (Cal Poly) was utilized to develop a method of creating a propulsion system for a hybrid powered sounding rocket. The methodology was derived from several sources. For instance, the scaling portion was derived from literature, while the structural analysis portion followed from course work at Cal Poly. Certain portions of the methodology were novel work. These included the oxidizer injector design and the ablative nozzle manufacturing process. The purpose of this section is to illuminate a path for future similar work.

\subsection{Similarity Scaling}

In order to facilitate the design of "similar" hybrid motors for this project, a MATLAB $^{\circledR}$ code was written. The MATLAB ${ }^{\circledR}$ code accepted performance requirements for the full scale hybrid motor and regression rate data from the lab scale motor to produce physical design parameters for both motors. The code was designed to increase the speed at which design iterations could be conducted. It took into account a number of the geometrical design constraints of the motors in order to limit the possible solution to only those that could be easily manufactured.

In previous work on scaling hybrid motors under similarity conditions, the equations have used the initial port diameter as a variable. This use of the initial diameter of the port can be problematic since configurations other than a simple circular port may be desired to be scaled. In order to account for non-circular geometries such as the port in a wagon wheel grain or for co-axial grain configurations an adaption can be made to the similarity equations. This adaption consists of replacing the initial port diameter with the average port hydraulic diameter. Utilizing average port hydraulic diameter in the 
similarity scaling code increased the functionality of the code across multiple port configurations. It should be noted that changing the grain configuration between "similar" motors was not investigated.

Due to the large ratios in some of the similarity parameters generated by having the two motors of significantly difference thrust, it can be difficult to achieve full similarity. For example, in the two motors designed as part of this project, the chamber pressure of the small scale motor was required to be 2000psi to achieve 550psi in the full scale motor while maintaining similarity (Table 3). This was a major limiting factor in how significantly different the thrust of the two motors could be since low chamber pressures could change the dominant physical transport phenomena in the motor and high chamber pressures would be impractical or prohibitively expensive for some oxidizers. Identifying acceptable deviation in chamber pressure while maintaining "similarity" is a topic which could warrant further research.

Table 3. Summary of Full Scale Versus Small Scale Motor Parameters

\begin{tabular}{|cccc|}
\hline Thrust & Full Scale & Small Scale & Units \\
\hline Burn Time & 2000 & 550 & $\mathrm{lbf}$ \\
\hline Chamber Pressure & 26 & 2 & $\mathrm{~s}$ \\
\hline Total Impulse & 550 & 2000 & $\mathrm{psi}$ \\
\hline Oxidizer Flow Rate & 52000 & 1100 & $\mathrm{lbf} * \mathrm{~s}$ \\
\hline Average Oxidizer Mass Flux & 8.61 & 2.37 & $\mathrm{lbm} / \mathrm{s}$ \\
\hline Oxidizer Mass Needed & 0.246 & 0.896 & $\mathrm{lbm} / \mathrm{in}^{\wedge} 2 / \mathrm{s}$ \\
\hline Fuel Grain Mass & 224 & 4.74 & $\mathrm{lbm} / \mathrm{s}$ \\
\hline Total Fuel Burned & 41.97 & 2.08 & $\mathrm{lbm} / \mathrm{s}$ \\
\hline Fuel Mass Flux & 28.5 & 1.05 & $\mathrm{lbm}$ \\
\hline Chamber Length & 0.00245 & 0.00510 & $\mathrm{lbm} / \mathrm{in}^{\wedge} 2 / \mathrm{s}$ \\
\hline Fuel Grain Outer Diameter & 20.75 & 10.91 & in \\
\hline Average Chamber Area & 10 & 3 & in \\
\hline Nozzle Throat Radius & 35 & 2.65 & in^2 \\
\hline
\end{tabular}




\subsubsection{Heavyweight Oxidizer Tank}

In a hybrid rocket, the oxidizer tank can have a significant impact on the mass ratio of the motor. The structural mass of the oxidizer tank can vary significantly if the hybrid motor is pressure fed vs. turbopump fed. Turbopump feed systems are the industry's current go-to feed system. The prevalence of turbopump fed propulsion systems can be traced back to the early days of the U.S.'s liquid rocket development program. In contrast to the standard, advances in composite technologies have made pressurized propellant tanks a possibility for flight tanks.

It is typical for prototype testing to utilize a design with high factors of safety, or "heavyweight" design for short. In order to create a heavyweight structure, it is typical to use a safety factor of four. This high factor mitigates the risk of unexpected catastrophic failures during the testing process which would hold up the development program. A heavyweight design for a hybrid rocket engine primarily focuses on the pressure rating of the oxidizer feed system and combustion chamber. The structure of the oxidizer tank and combustion chamber are often cylindrical due to their preferentially high contrast ratio for launch vehicles. The force in a cylindrical pressure vessel (Equations $1 \& 2$ ) must be satisfied using appropriately robust structures.

$$
\begin{array}{ll}
\boldsymbol{S}_{\boldsymbol{x}}=\frac{\boldsymbol{p} \times \boldsymbol{r}}{2} & \text { Equation 1 } \\
\boldsymbol{S}_{\boldsymbol{y}}=\boldsymbol{p} \times \boldsymbol{r} & \text { Equation 2 }
\end{array}
$$

where $S$ is the load on the structure, $p$ is the pressure in the cylinder, and $r$ is radius of the cylinder.

A simple heavyweight oxidizer tank configuration consists of a cylinder captured by end caps which are themselves captured by multiple threaded rods (Figure 7). The 
cylinder is responsible for taking the entire hoop loading, the end caps seal the end of the cylinder, and the threaded rods take all of the longitudinal loading.

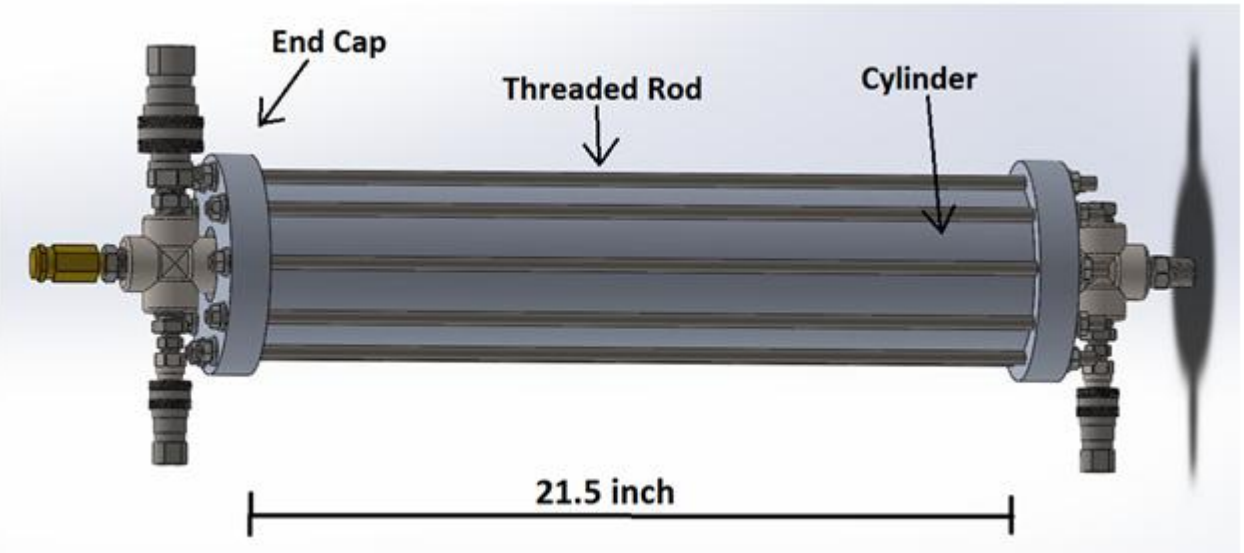

Figure 7. Heavyweight Oxidizer Tank Design

The analysis of the structure can be quite simple as long as the aspect ratio of the cylinder remains below 10:1 which allows for the thin walled assumption. The thin walled assumption states that the hoop stress in a cylinder can be calculated using Equation 3. By using threaded rods manufactured to a specification such as ASTM, SAE or ISO, the longitudinal load (Equation 2) can be easily restrained by using the appropriate number of threaded rods. The heavy weight pressure vessel created for this work had a mass fraction of $85 \%$.

$$
\sigma_{x}=\frac{p \times r}{2 t}
$$

\subsubsection{Combustion Chamber}

The combustion chamber of a rocket motor is a very energetic environment and thus has uniquely difficult loading conditions to consider in the design. Both the combustion temperature and pressure are extreme with temperatures as high as $5000^{\circ} \mathrm{F}$ 
and pressures up to 1000 psi typically. In a hybrid rocket motor the solid fuel grain acts as an ablative thermal insulator for the chamber so, much of the thermal loading which solid or liquid rocket motors see is not an issue. The injector sits above the fuel grain in the combustion chamber and serves as the fore enclosure for the combustion chamber. The oxidizer injector's main purpose is to spray the oxidizer into the chamber at a metered rate. The injector configuration can have a significant impact on the efficiency and stability of combustion. The nozzle sits below the fuel grain in the combustion chamber and serves as the aft enclosure. The nozzle also accelerates and expands the combustion gasses efficiently so as to transfer as much potential energy into kinetic energy as possible. The combustion chamber walls hold the other components together and take the majority of the loading from the chamber pressure (Figure 8).

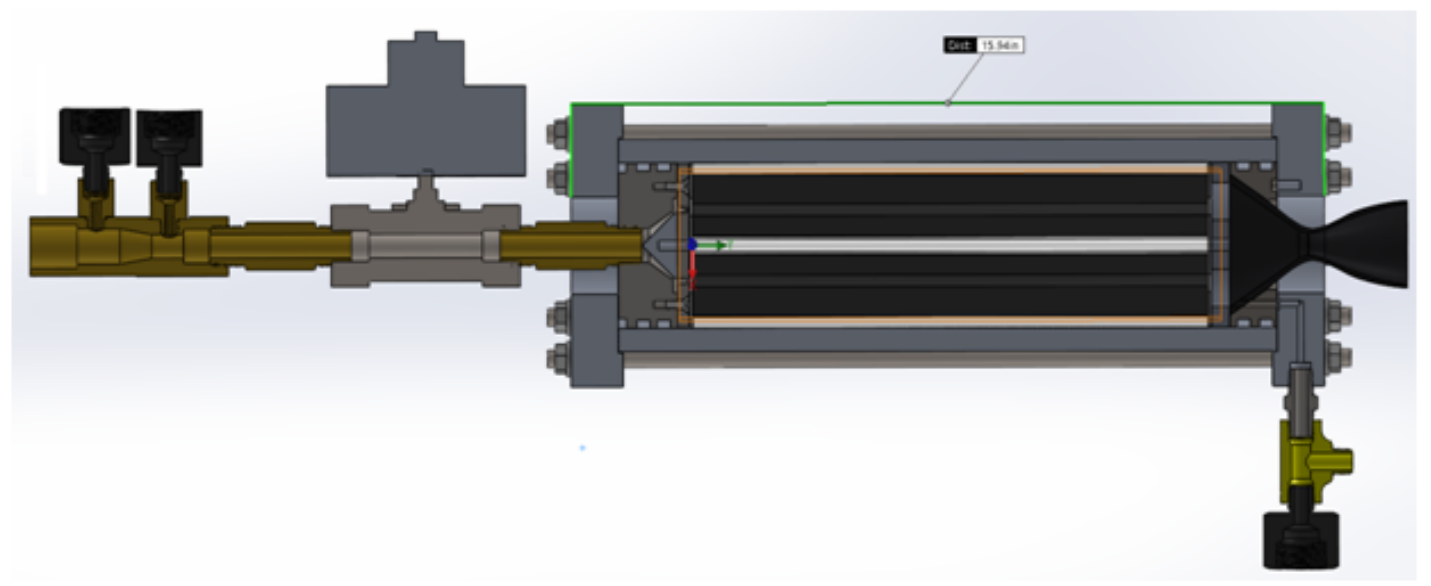

Figure 8. Small Scale Hybrid Rocket Motor

\subsubsection{Chamber Walls}

The combustion chamber walls are primarily responsible for taking the loading from the chamber pressure. Since the loading for a hybrid rocket motor's combustion chamber is very similar to that of a normal pressure vessel, similar design methodologies 
can be used, especially for small scale ground testing activities. For this project the small scale combustion chamber has been designed almost identically to the heavyweight oxidizer tank design in order to minimize design work. The only difference in the design is that the length of the combustion chamber is shorter than the oxidizer tank (Figure 9).

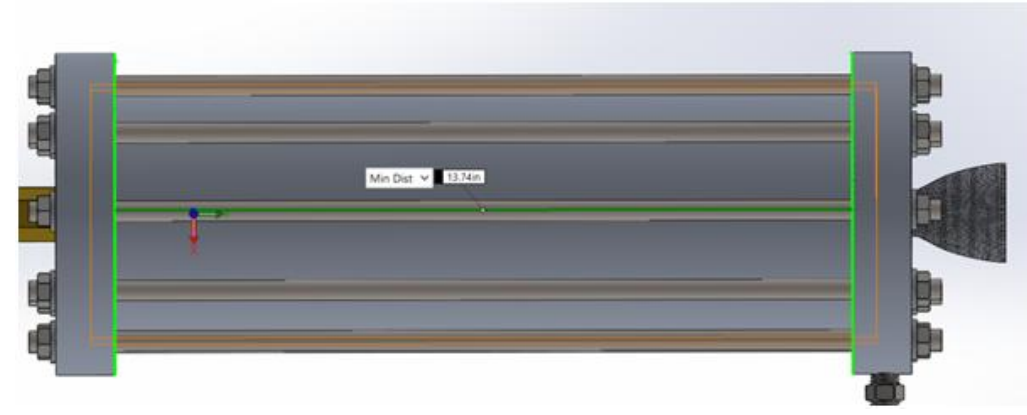

Figure 9. Heavyweight Combustion Chamber

\subsubsection{Fuel Grain}

Hybrid rocket motors usually have a relatively simple fuel grain configuration as compared to solid rocket motors. Most lab or demonstration motors use a single circular port for the combustion chamber. In larger flight application motors a wagon wheel design is utilized for the fuel grain. The reason for the simple circular port is that it is more easily manufactured and modeled than other port designs. It is typical for researchers to begin work on a model using a 1-dimentional model and a planar slab configuration combustor. Research work usually then progresses to a two dimensional model and uses a simple circular port motor for testing. However, the wagon wheel port configuration has the advantage of a greater surface area which results in higher thrust produced by the motor for a given diameter. The wagon wheel port is commonly used for full scale applications because it produces greater volumetric thrust (Figure $10 \mathrm{~A}$ ). One 
disadvantage for these common grain configurations is that the fuel grain surface area increases as the fuel burns away. The constantly changing fuel grain surface area causes the oxidizer to fuel ratio in the combustion chamber to change throughout the entirety of the motor burn.

The co-axial fuel grain configuration has the unique advantage of maintaining a constant fuel surface area in the combustion chamber during a burn. A co-axial fuel grain configuration is where there are two separate fuel grain which share the same axis in the combustion chamber. For this project, the outer fuel grain is a simple circular fuel grain while the inner fuel grain is a simple circular rod. As the outer fuel grain regresses outward and the inner fuel grain regresses inward the surface area of fuel in the combustion chamber remains constant as long as both the inner and outer fuel grains have the same regression rate (Figure $10 \mathrm{~B}$ ). Having a constant surface area throughout the burn correlates to having a constant fuel mass flux and is preferred for maintaining a specific fuel to oxidizer ratio. The constant mass flux advantage of the coaxial grain configuration is why it was chosen for use in this work since keeping things constant during the burn helps the similarity extrapolation between two motor's mass flux.

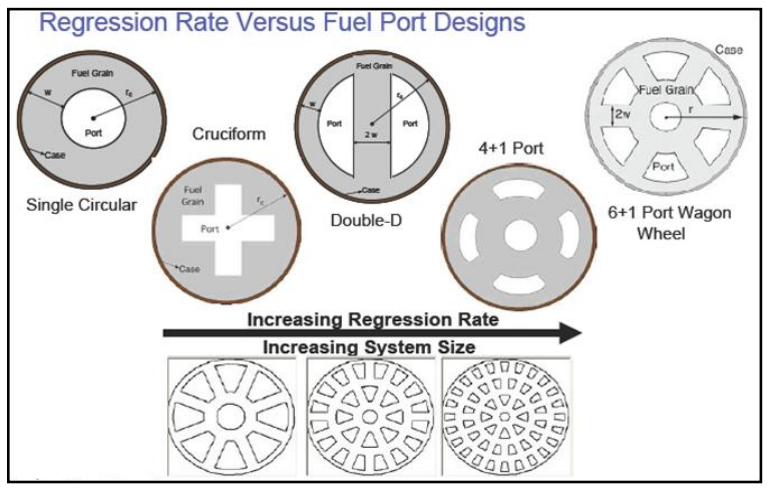

A)

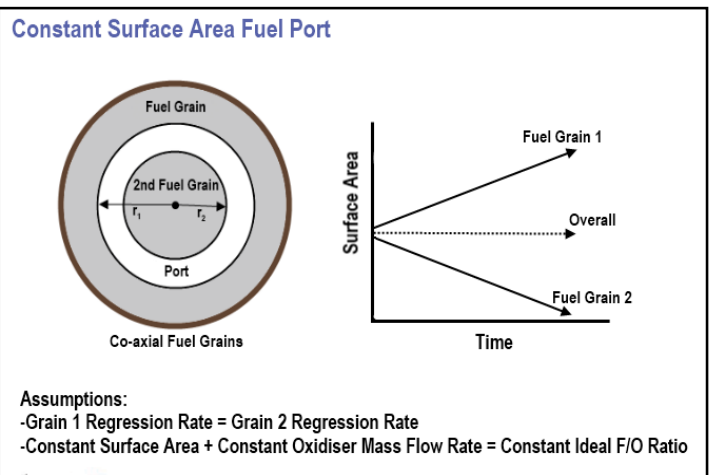

B)

Figure 10. Fuel Grain Port Geometry 


\subsubsection{Injector}

In order to effectively inject oxidizer into the combustion chamber a suitably designed injector is necessary. For this project a thirty-two port self-impinging swirl injector was used (Figure 11). The injector was based on a previously used injector from Arena et al. [9] but modified for use with coaxial fuel grains.

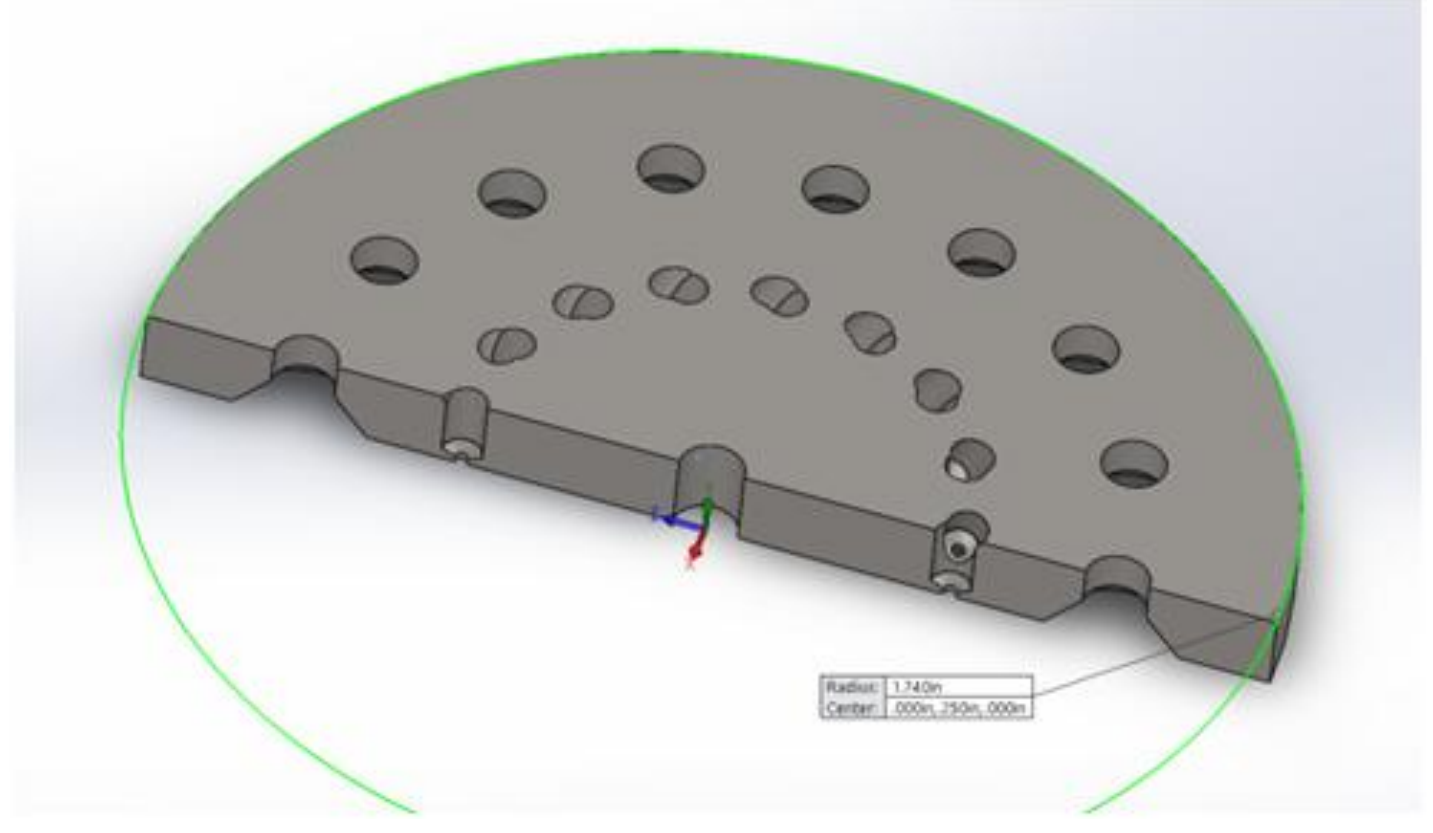

Figure 11. Injector Plate Section View

The design of the injector was intended to spray oxidizer on the central fuel rod grain and to force oxidizer onto the outer circular fuel grain. Each of the thirty-two individual oxidizer injectors sprayed liquid oxidizer half way into another oxidizer stream which is the basis of the "self-impinging" title. Sixteen sets of impinging injectors form a ring at the midpoint between the two fuel grains. Part of the resulting oxidizer stream swirls at roughly $20^{\circ}$ as it travels down the combustion chamber port forcing some of the oxidizer towards the outer grain as seen in the water flow test in Figure 12. 


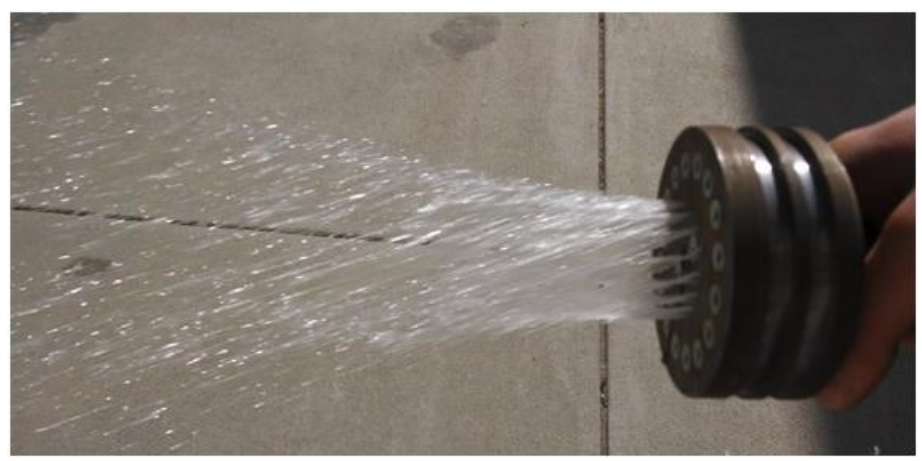

Figure 12. Injector Water Flow Visualization

The injector was initially analyzed using Solidworks FloXpress Analysis Wizard. The simulation was set up to run $2.51 \mathrm{bm} / \mathrm{s}$ of water through the model with an exit pressure of one atmosphere. This simulation which is depicted in Figure 13 shows that the flow through the chamber should swirl as designed.

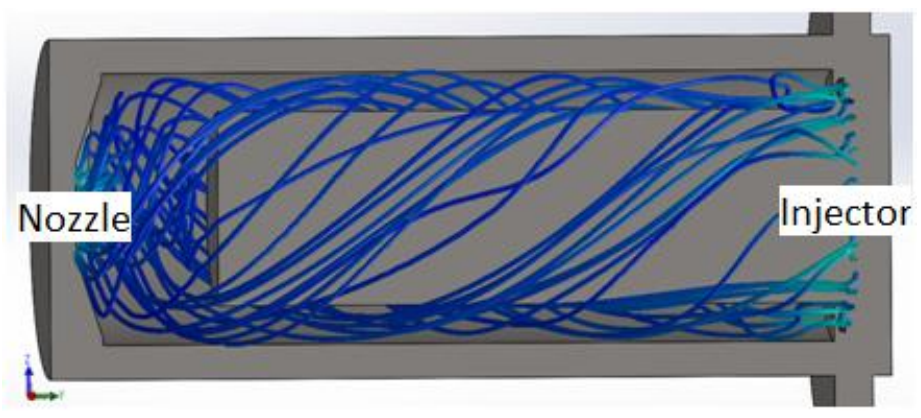

Figure 13. CFD Model of Oxidizer Flowing Through Combustion Chamber

The thirty-two self-impinging swirl injectors were machined in an interchangeable injector plate (Figure 14). The injector plate was attached to the injector assembly using sixteen flat-head socket cap screws. Having an interchangeable injector plate makes it easier to modify the injector deign if necessary. The number of injector ports was maximized for the space available in the small scale motors initial port. Having the most ports possible was chosen so that the oxidizer would enter the combustion 
chamber evenly around the radius of the combustion port. The radius of the injector ports $\left(\mathrm{r}_{\mathrm{inj}}\right)$ was determined using Equation 4. Equation 4 is the equation for the mass flow rate through an orifice solved for injector radius rather than mass flow rate.

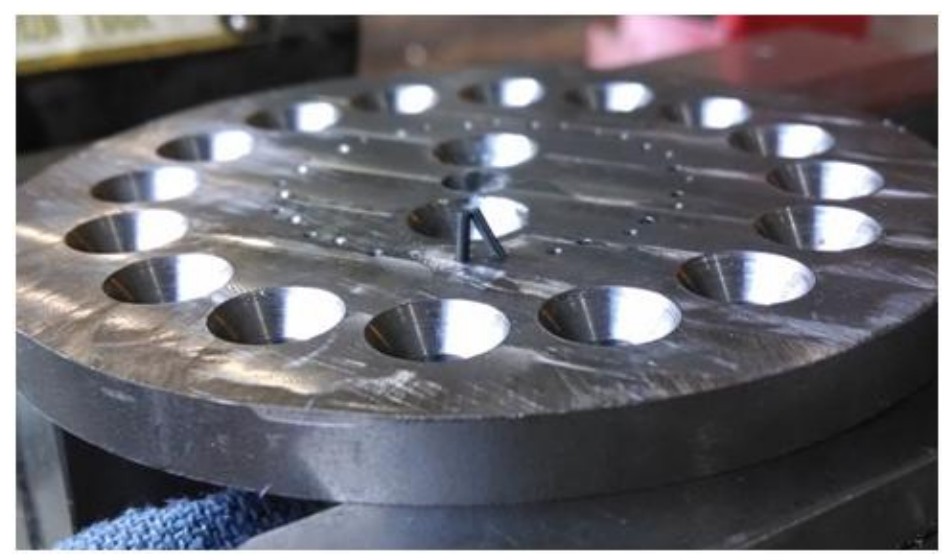

Figure 14. Injector Plate

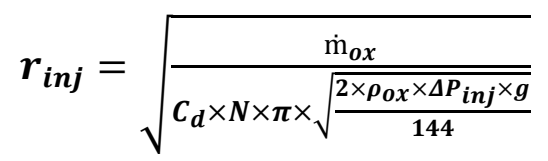

Equation 4

\subsubsection{Nozzle Design}

Nozzles are important for getting all the energy possible out of a rocket motor. A nozzle efficiently expands and accelerates the hot gases generated by a rocket motor. In order to design a nozzle, one must start by deciding upon the design technique for the internal contour. The simplest design is a conical nozzle, followed by a parabolic approximated bell nozzle; and the most involved design being the bell nozzle designed using the Method of Characteristics (MoC). All three of these techniques can be used to develop a nozzle which will work. However, greater efficiency can be gained by using a more advanced technique. Since a bell nozzle which is $80 \%$ of the length of a conical nozzle can achieve over 98.5\% efficient gas expansion, bell nozzles are typically utilized on rockets due to the weight savings. The parabolic approximation method for designing 
a bell nozzle is quite a bit faster and easier than developing a program which utilizes the MoC or by doing the MoC by hand to design a nozzle. The parabolic approximation method is relatively easy to use compared to the $\mathrm{MoC}$ while maintaining high thermodynamic and weight efficiency which is the reason it was the design method chosen for this project. The internal contour of the nozzle for the rocket motor was designed to be optimally expanded at 25,000ft above ground level (Table 4).

Table 4. Nozzle Design Parameters

\begin{tabular}{|ccccccc|}
$\begin{array}{c}\text { Design } \\
\text { Altitude (ft) }\end{array}$ & $\begin{array}{c}\text { Pressure } \\
\text { Ratio }\end{array}$ & $\begin{array}{c}\text { Expansion } \\
\text { Ratio }\end{array}$ & $\begin{array}{c}\text { Length } \\
\text { (in) }\end{array}$ & $\begin{array}{c}\text { Throat Diameter } \\
\text { (in) }\end{array}$ & $\begin{array}{c}\text { Exit Diameter } \\
\text { (in) }\end{array}$ & $\begin{array}{c}\text { Expected } \\
\text { Efficiency }\end{array}$ \\
\hline 25,000 & 177 & 13 & $2.1 "$ & 0.475 & 1.713 & $99 \%$ \\
\hline
\end{tabular}

The other challenge in rocket nozzle design is material selection. The combustion gases which are generated by a rocket motor are in the thousands of degrees; well above the melting point of all materials except for refractory metals or ceramics. The high temperatures and pressures that the nozzle is subject to limits the choice of materials for manufacturing. There are few ways to design a nozzle to overcome these challenges. One way is to use a metal nozzle which has high thermal conductivity and high thermal mass but a melting temperature below the temperature of the combustion gases. As long as the metal can conduct the heat away from the inner walls of the nozzle fast enough and the burn time is short enough then it will not reach its melting temperature and the nozzle will successfully do its job and survive. Copper is a common material for use in this type of nozzle design.

Another nozzle thermal design which can be used is similar to the high thermal mass nozzle but instead of relying on the metal's thermal mass it utilizes a coolant flowing through the nozzle to take away the heat. This design is known as a 
regeneratively cooled nozzle. Regenerative cooling does not have a time limit of operation like the high thermal mass metallic nozzle. Many liquid propellant rocket engines use their fuel to regeneratively cool the nozzle. In a hybrid rocket engine this is not possible since the fuel is solid instead of a liquid. Using the hybrid rocket motor's liquid oxidizer to regeneratively cool the nozzle is quite difficult due to phase change and decomposition concerns. The other nozzle thermal design is the ablatively cooled nozzle which is most common for solid rocket motors. An ablative nozzle is made from a substance that burns slowly and produces gas which protects the rest of the nozzle from the heat. Ablative nozzles can only be used once but can be lightweight and simpler than other designs. Because a hybrid rocket's solid fuel grain is somewhat similar to a solid fuel rocket motor, an ablative nozzle design may be optimal for a given sounding rocket design but does have development challenges.

The process for manufacturing an ablative nozzle is something that is hard to find references on. Most ablative nozzle manufacturing techniques are either proprietary information or may be restricted from the public domain by International Traffic in Arms Regulations (ITAR). These restrictions make it difficult to find publically available information on this subject which leaves the small scale and amateur rocket community with a gap in information on this subject. In spite of this gap, Section 4.2 presents a novel manufacturing process which was developed for use on small scale sounding rocket projects. The process presented may be useful on larger scales but herein has only been demonstrated for a small scale testing applications. 
Two different nozzle thermal designs were built for this project. Both a steel high thermal mass nozzle and an ablative carbon fiber-phenolic composite nozzle were manufactured.

\subsection{Weight Minimization by Utilizing a COPV}

Classical laminate theory (CLT) is a widely used technique to determine the strength of composite structures. CLT can be used for COPV analysis by assuming that the layers of the COPV can accurately be modeled as a flat plate loaded in the $\mathrm{X}$ and $\mathrm{Y}$ axes (Figure 15). The loads can be calculated using the thin walled cylinder equilibrium equations (Equations 1\&2).

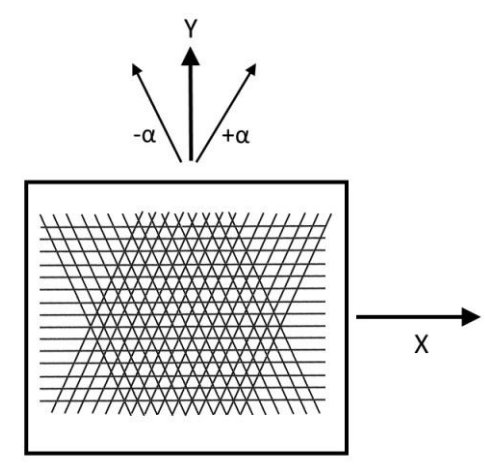

Figure 15. Laminate Diagram

The failure criteria utilized in the analysis for this project was the maximum stress $\left(\sigma_{\max }\right)$ of the composite laminate. This is the most simplistic failure criteria but serves adequately for the loading condition of a pressurized cylinder. The failure in the domes (end enclosures of the cylinder) was not calculated because it is typical for the domes to be over designed, forcing the failure to occur in the cylindrical section. Accurate prediction of COPV dome failure has proven difficult and is not a preferred failure mode for safety reasons. A stress concentration at the dome-cylinder interface also leads to over designed domes in order to force the failure in the more predictable cylinder region ${ }^{8}$. 
In order to verify the utility and efficiency of using a COPV as an oxidizer tank in a launch vehicle, a prototype pressure vessel was built and hydrostatically tested for this project. The carbon fiber tow utilized in the wet filament winding process of making the vessel was first tested. Utilizing the tensile data gathered on the carbon fiber and resin system utilized for the COPV, an Excel ${ }^{\circledR}$ tool was created to predict the failure pressure using CLT. Utilizing a modified 2-axis filament winder, the prototype COPV was filament wound over a polymer liner made from two 2-liter soda bottles (Figure 16). This liner was extremely easy to procure and thus offered a great benefit in the prototyping process. The COPV was then hydrostatically tested and the results of the test were compared to the predictions from the Excel ${ }^{\circledR}$ tool.

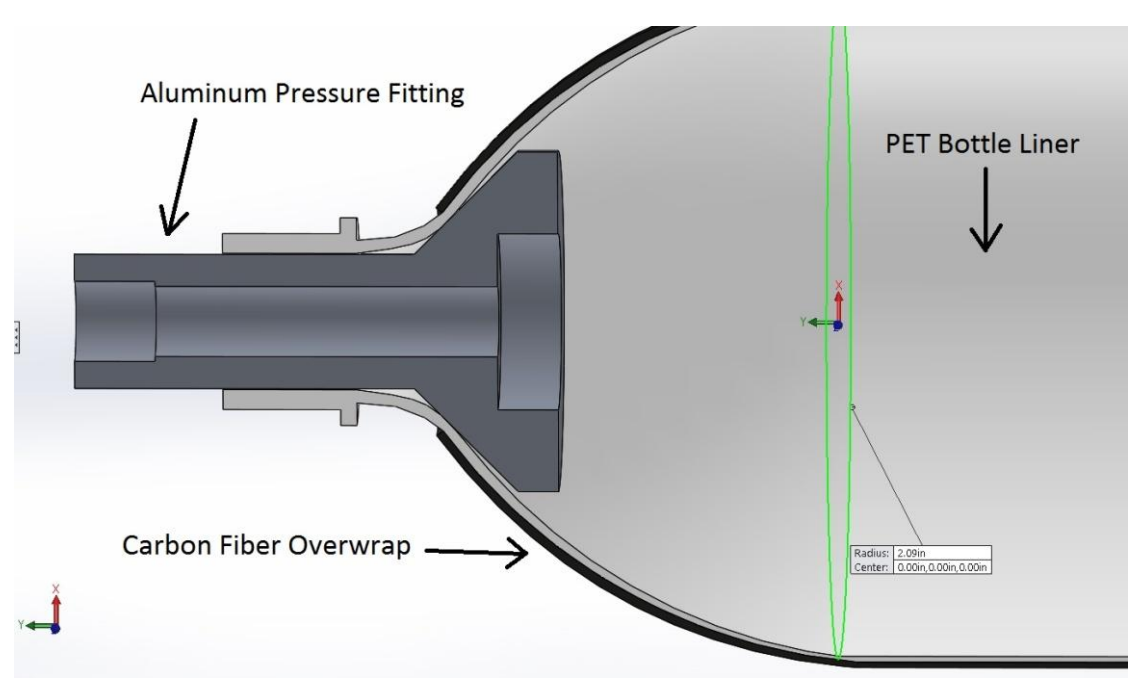

Figure 16. COPV Cross Section

The COPV created was about $35 \%$ smaller in volume than the heavy weight vessel created for ground testing of similarity scaling. It also had a much lower design pressure. A COPV with the same design pressure as the heavy weight vessel but would have had a mass fraction of $58 \%$. 


\section{MANUFACTURING}

The techniques utilized for manufacturing rocket systems are often considered proprietary and information on them is hard to gather. Some manufacturing processes utilized for this work are discussed to aid in future work.

\subsection{Similarity Scaling}

The manufacturing process for the injector and nozzle can be complex. The process utilized to create both the injector plate and nozzles are covered in the report.

\subsubsection{Injector}

In order to machine the injector plate, a disc of 1215 carbon steel was secured in a rotary chuck on a mill table. The head of the mill was capable of rotating to create the compound angle operation on the injector plate for the secondary impinging oxidizer ports (Figure 17). The ports were counter sunk on the upstream side of the injector plate so that the restricting port diameter had an aspect ratio of less than or equal to 1:1. Capping the aspect ratio at 1:1 helps to get predictable mass flow rates through the injectors. Some oxidizers such as nitrous oxide will go through a phase change in the injector ports so that there is two-phase-flow which dramatically reduces the mass flow rate through the orifice. Low aspect ratios in injector ports help to prevent the negative effects of two-phase-flow on the mass flow rate through the injectors. 


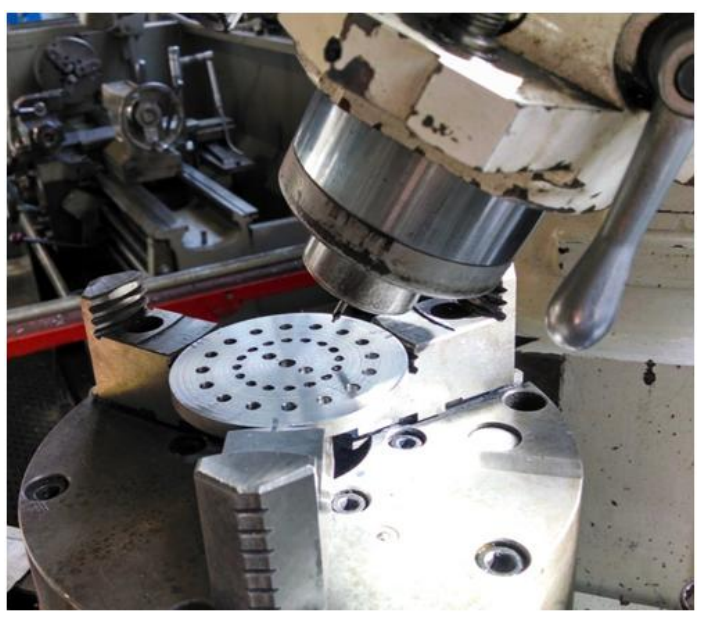

Figure 17. Injector Plate Machining

\subsubsection{Steel Nozzle}

A high thermal mass steel nozzle was initially made for testing (Figure 18). The nozzle was made from 1215 carbon steel because of its machining properties. The nozzle was made on a computer numerical controlled (CNC) lathe in order to achieve the internal curves.

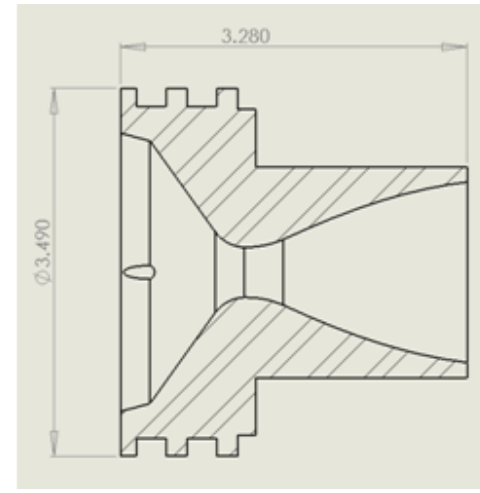

A)

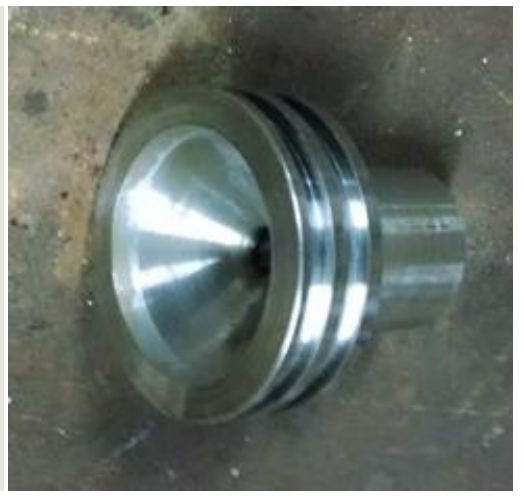

B)

Figure 18. Steel Rocket Nozzle 


\subsection{Weight Minimization by Utilizing a Phenolic Nozzle}

Composite technology is an effective tool for minimizing the weight of a structure. Both an oxidizer tank and a nozzle were create for this project using composites. Carbon fiber is an attractive material for an ablative nozzle because of its high temperature resistance. Cytec L-802 phenolic pre-impregnated (pre-preg) carbon fiber/fiber glass was chosen for use in the ablative nozzle. Tensile test samples were first made using the L-802 material to get accurate material properties for use in the design of the nozzle (Table 5).

Table 5. Carbon Fiber Phenolic Laminate Tensile Test Results

\begin{tabular}{|lccc|} 
& $0^{\circ}$ & $90^{\circ}$ & $45^{\circ}$ \\
\hline Ultimate Tensile Strength (ksi) & 162.4 & 150.6 & 23.15 \\
\hline Strength Standard Deviation (ksi) & 15.07 & 3.59 & 0.23 \\
\hline Tensile Modulus (ksi) & 5,136 & 5,713 & 4,420 \\
\hline Modulus Standard Deviation (ksi) & 383.8 & 216.3 & 107.4 \\
\hline Number of Samples Tested & 3 & 3 & 3 \\
\hline
\end{tabular}

The thermal characteristics were assumed to be similar to those reported in Ref.

10. In testing monolithic graphite ablative nozzles it was found that designing the combustion of the hybrid motor to be fuel rich would significantly diminishes ablation and lengthen the time an ablative nozzle could last. The final nozzle laminate design took into account the thermal and structural loading that the nozzle was expected to see with a FoS of 4 for each loading condition. (Figure 19, A). The manufactured nozzle exceeded the design thickness of the nozzle to allow for material removal and shaping (Figure 19, B) 


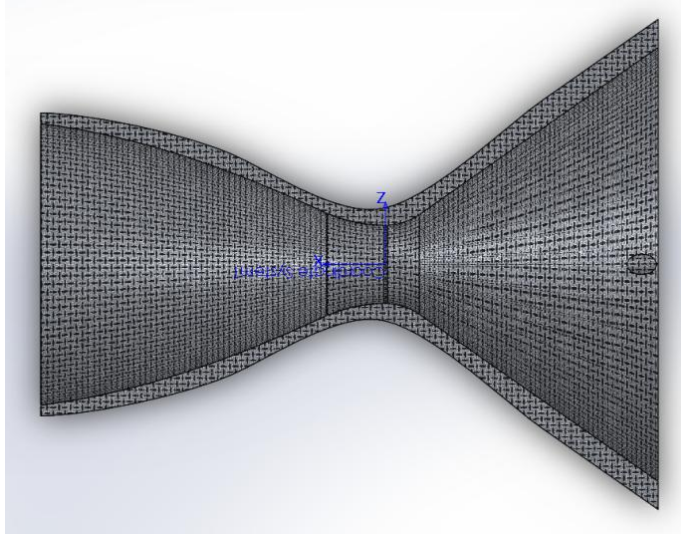

A)

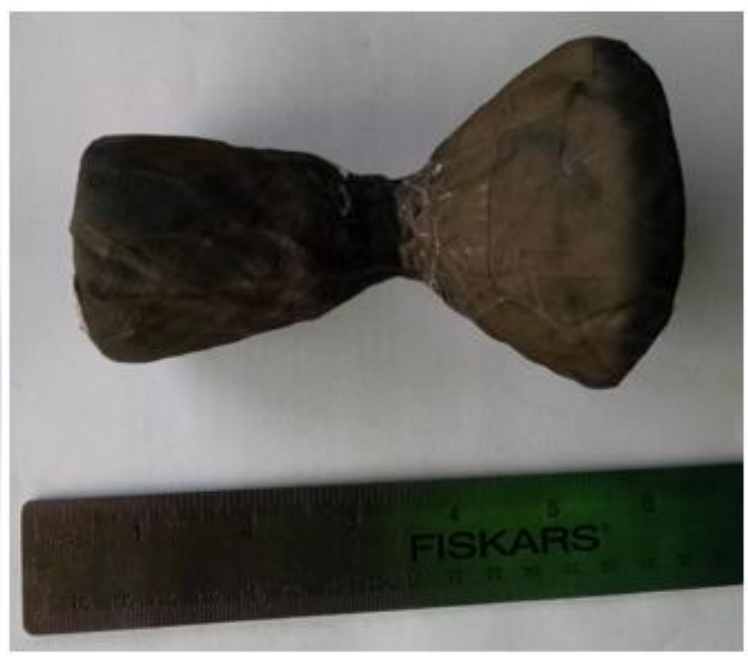

B)

Figure 19. Carbon Fiber Phenolic Nozzle

Four hundred and seventy-two square inches of L-802 pre-preg material were utilized in the ablative nozzle (Figure 20 A). The laminate was cut into multiple small strips to allow for even coverage of the mandrel (Figure $20 \mathrm{~B}$, Table 6).

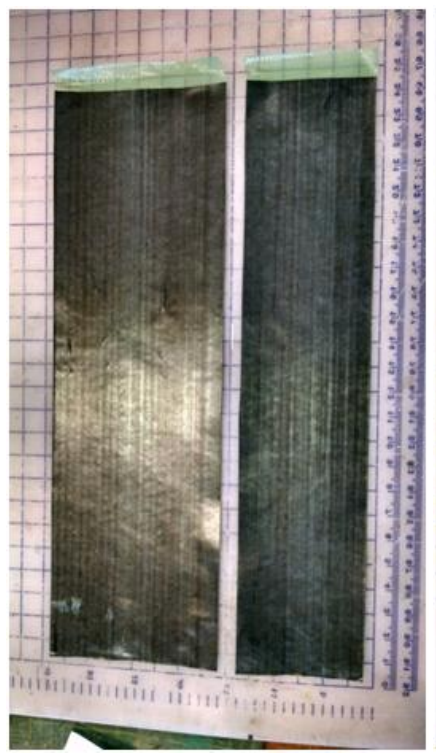

A)

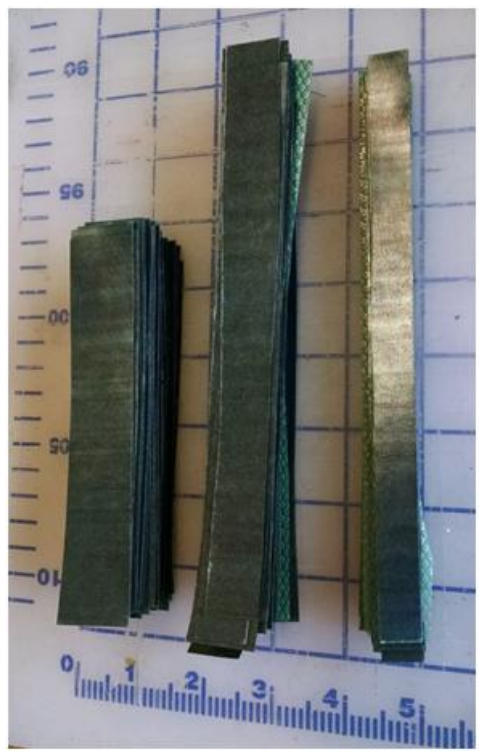

B)

Figure 20. Carbon Fiber Phenolic Sheet and Strips 
Table 6. Carbon Fiber Phenolic Strip Dimensions

\begin{tabular}{|llll|} 
& Strip 1 & Strip 2 & Strip 3 \\
\hline Size (in) & $1 \times 5$ & $0.75 \times 7.25$ & $0.5 \times 7.25$ \\
\hline Number Cut & 48 & 32 & 16 \\
\hline
\end{tabular}

The process of laying up the ablative composite nozzle began by preparing the mandrel. The mandrel was first assembled and the central threaded shaft was tightened to ensure the geometry didn't shift during use. Next, the mandrel was cleaned and flash breaker tape was adhered to the parts which where excess laminate would be to help post cure disassembly. A strip of laminate was wrapped around the top and bottom of the mandrel to help later strips adhere at that point as well (Figure 21 A). Mold release was then applied to the mandrel to help later disassembly. Starting with material from the Strip1 pile the converging portion of the mandrel was covered (Figure $21 \mathrm{~B}$ ). The strips were laid down, starting at the cylindrical portion of the mandrel, tangent to the four quadrants on the mandrel (Figure $21 \mathrm{C}$ ). This process was repeated twice to fully cover the converging section of the mandrel (Figure $21 \mathrm{D}$ ). A similar process was conducted on the diverging portion of the nozzle except with material from the pile designated Strip 2 (Figure $21 \mathrm{E}$ ). To bridge the gap on the mandrel around the throat, material from pile designated Strip 3 was wrapped around the whole mandrel in a helix starting at the bottom and wrapping around the throat a half rotation before continuing to the top (Figure $21 \mathrm{~F}$ ). After four helix strips and been laid down around the throat, tape was used to consolidate the material there and help avoid the presence of voids in the laminate (Figure $21 \mathrm{G}$ ). The tape was then removed. After repeating the process for three more layers, the excess material around the top and bottom of the mandrel was cut off to help in the later disassembly of the mandrel (Figure $21 \mathrm{H}$ ). The axial orientation of the strips 
in each layer was rotated $45^{\circ}$ around the center axis of the nozzle to provide a more even final layer distribution.

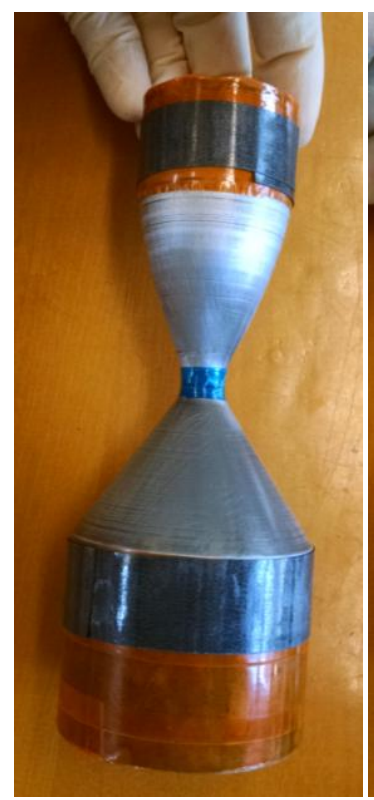

A)

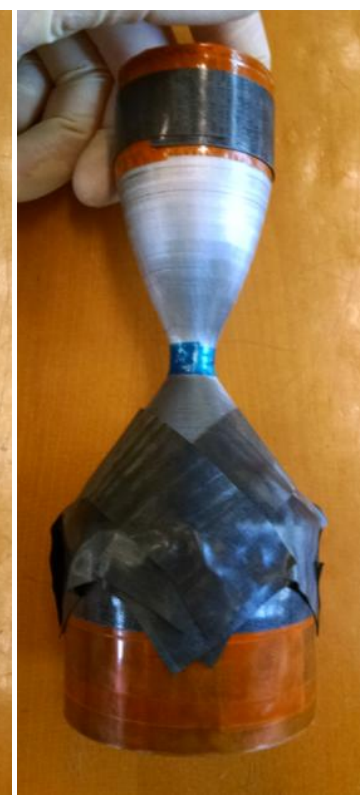

B)

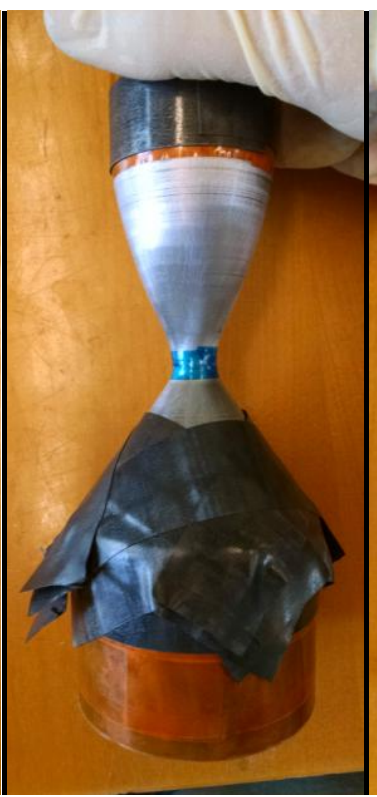

C)

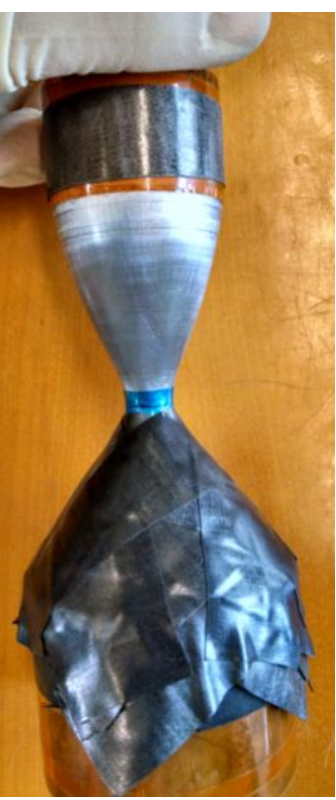

D)

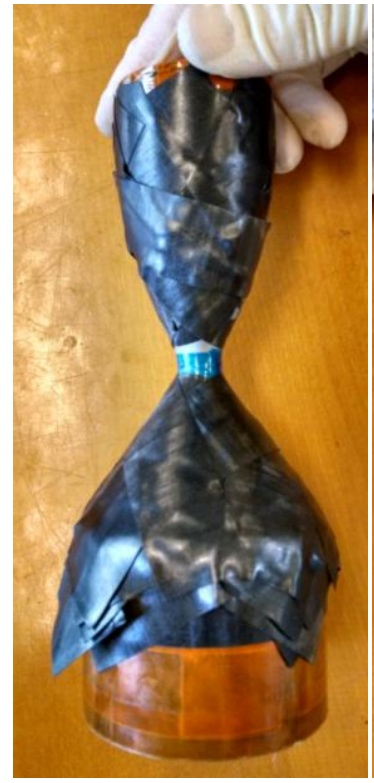

E)

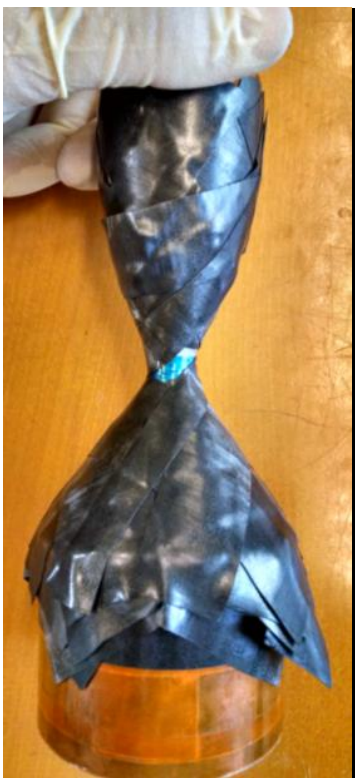

F)

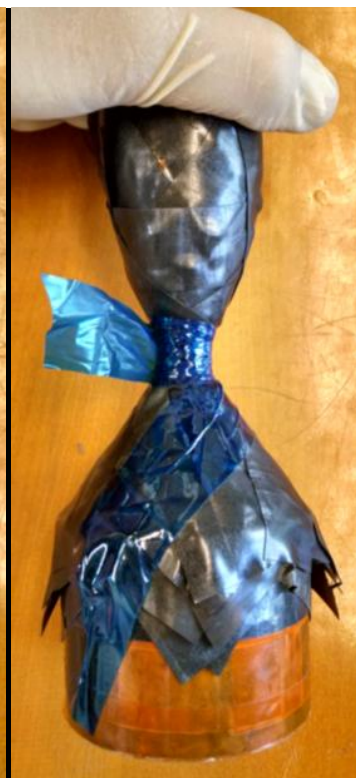

G)

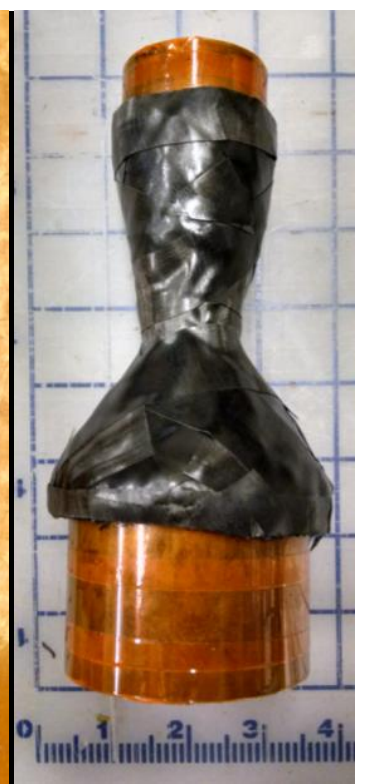

$\mathrm{H})$

Figure 21. Carbon Fiber Phenolic Nozzle Layup Process

The nozzle laminate and mandrel were then wrapped in peel-ply and batting and sealed in a vacuum bag. The laminate was cured in an autoclave at $275^{\circ} \mathrm{F}$ for 90 minutes. 
After removing the mandrel from the cured nozzle the external surface of the diverging portion of the nozzle was machined to match the conical surface of its holding fixture (Figure 22).

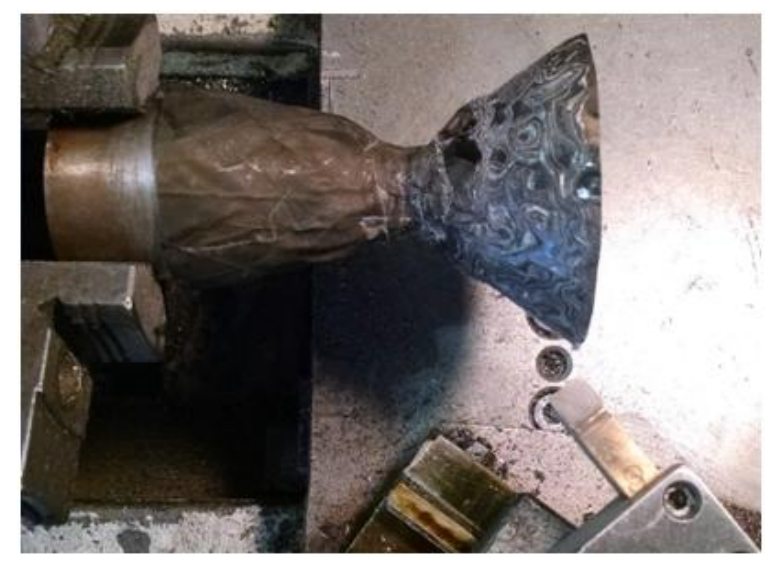

Figure 22. Carbon Fiber Phenolic Nozzle Machining

It is important for the layup of the composite nozzle to have a consistent internal contour. Any defects in the nozzle, especially in the diverging section, could cause separation of the flow from the wall and a significant loss in efficiency. After eight iterations, a defect free composite nozzle was created for this project (Figure 23).

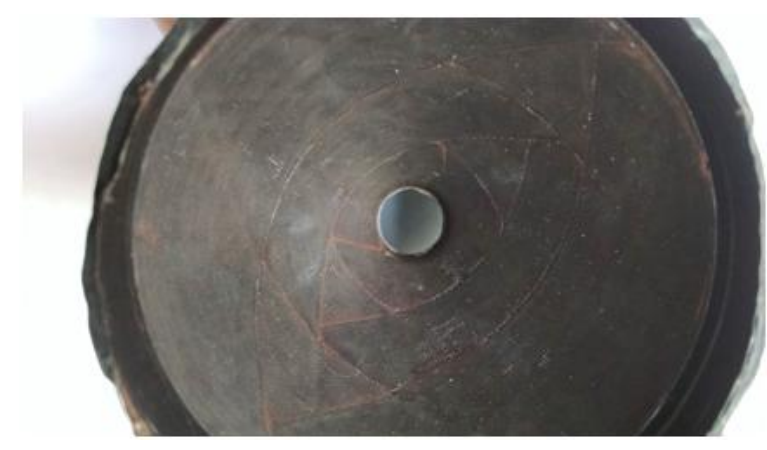

Figure 23. Carbon Fiber Phenolic Nozzle Converging Section 


\section{TEST STAND AND INSTRUMENTATION}

In order to verify the results of ground testing, an instrumented test stand was necessary. The test setup utilized available hardware supplemented with new sensors and data acquisition equipment.

\subsection{Test Stand}

The test stand utilized for this project had been developed as part of a senior project for a student in the Cal Poly Aerospace Engineering Department in 2006 [11]. The motor was attached to the linear bearings on the thrust measurement stand while the oxidizer tank was hung from a separate stand (Figure 24). The test stand is rated for 1200 pounds of thrust. The intended thrust of the small scale hybrid motor was 600 pounds. The test stand was fixed to the ground in the courtyard of the propulsion test facility at Cal Poly.

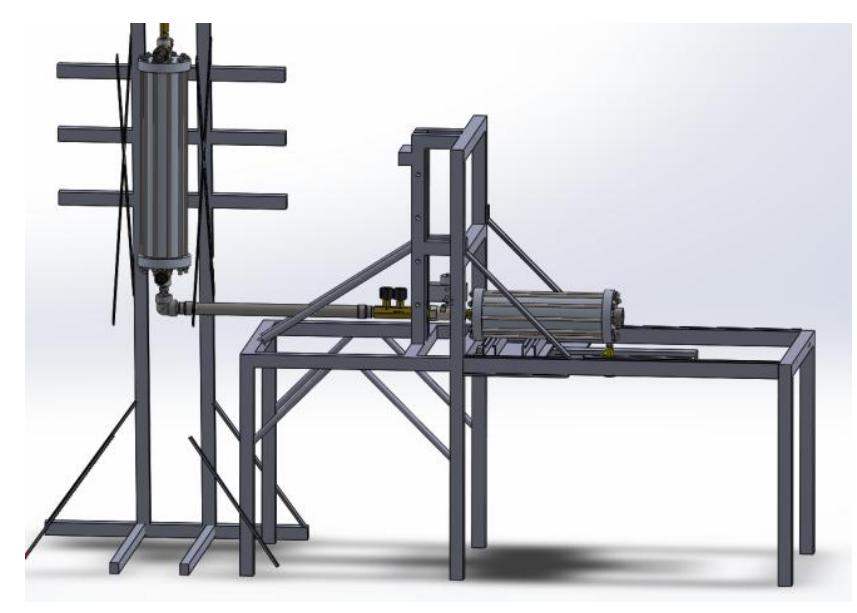

Figure 24. Small Scale Hybrid Rocket Motor on Test Stand

\subsection{Thrust Measurement}

In order to measure the thrust produced by the rocket motor on the test stand, an Omega load cell was utilized (Figure 25). The load cell was rated to 1000 pounds. The injector of the hybrid motor presses against a pivoted arm which in turn transfers thrust 
from the motor to the load cell. The load cell was calibrated with weights before testing to ensure accuracy of the measurement.

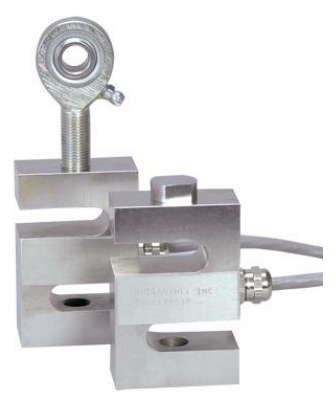

Figure 25. Omega LC101 Load Cell

\subsection{Oxidizer Tank Load Cell}

In order to determine the amount of oxidizer in the oxidizer tank the entire tank was hung from another Omega load cell (Figure 25). This load cell was rated to 500 pounds. A short piece of rope suspended the tank from the load cell which was attached to a metal support structure. The only other attachment to the tank was a flexible 18 " hose connecting the tank to the oxidizer valve.

\subsection{Pressure Measurement}

The combustion chamber pressure was measured using a Wika type A-10 general purpose pressure transducer rated to 3000psi (Figure 26). The pressure transducer was attached to a filter to prevent damage from the combustion gasses and soot. The filter was then attached to the end plate which held the nozzle in place. The nozzle and end plate had passages drilled in them to allow combustion gasses to reach the fitting which the filtered pressure transducer was attached to (Figure 27). The Wika pressure transducers were also utilized for measuring the pressure during hydrostatic testing of the COPV. 


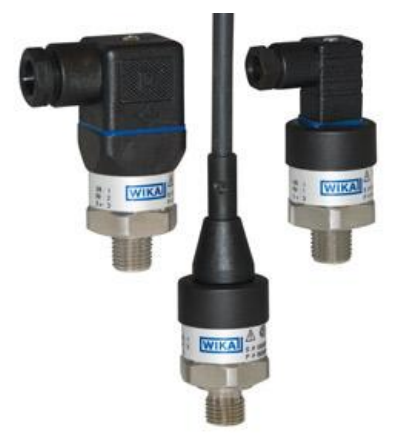

Figure 26. Wika Type A-10 Pressure Transducer

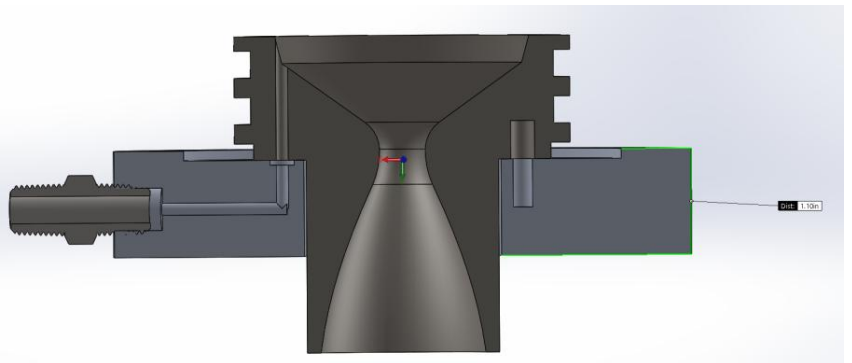

Figure 27. Chamber Pressure Port

\subsection{Oxidizer Flow Measurement}

To measure the mass flow rate of the oxidizer flowing to the hybrid motor during testing, a venturi volumetric flow meter was designed and manufactured (Figure 28). The venturi can be used to find a flow rate by measuring the pressure differential between two different sized cross sections as the oxidizer flows through it. Generally the difference in the pressure of the flow is measured between the typical system pipe size and a constriction which opens to the typical pipe size again. In the configuration used for this motor the feed tube needed to be reduced from $3 / 4$ " to $1 / 2$ " just before the injector so the venturi was designed to only constrict the flow and not re-expand it. 


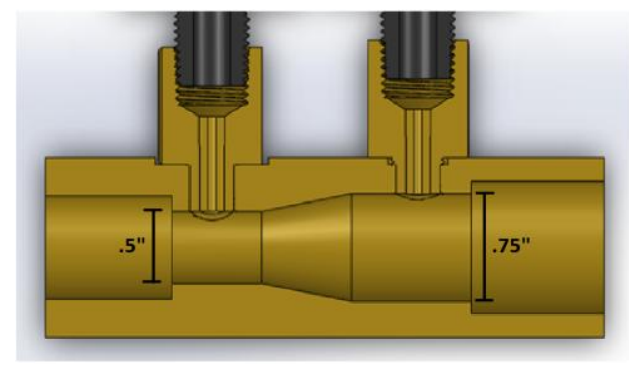

Figure 28. Oxidizer Venturi

\subsection{Data Acquisition Devise}

The data from the various sensors used during testing was collected by a data acquisition device made by National Instruments (NI). The device used was a NI USB6210 DAQ (Figure 29). The DAQ was interfaced with a computer running LabView ${ }^{\circledR}$ software to collect and store the data. The sensors which were wired into the DAQ are summarized in Table 7.

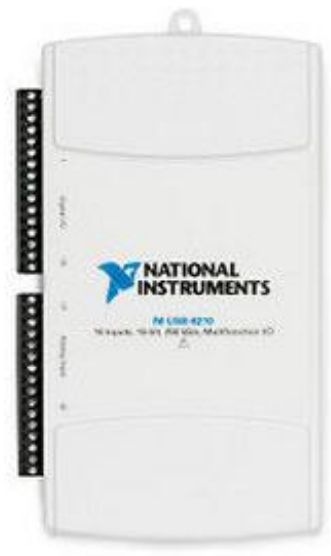

Figure 29. National Instruments USB-6210 DAQ

Table 7. Summary of Data Channels Collected

\begin{tabular}{|ccccccc|}
\hline Channel & 1 & 2 & 3 & 4 & 5 & 6 \\
\hline Sensor & $\begin{array}{c}\text { Weight } \\
\text { Load Cell }\end{array}$ & $\begin{array}{c}\text { Thrust } \\
\text { Load Cell }\end{array}$ & $\begin{array}{c}\text { Venturi 1 } \\
\text { Pressure }\end{array}$ & $\begin{array}{c}\text { Fill } \\
\text { Pressure }\end{array}$ & $\begin{array}{c}\text { Chamber } \\
\text { Pressure }\end{array}$ & $\begin{array}{c}\text { Venturi 2 } \\
\text { Pressure }\end{array}$ \\
\hline Max Reading & $500 \mathrm{lb}$ & $1000 \mathrm{lb}$ & $3000 \mathrm{psi}$ & $1000 \mathrm{psi}$ & $3000 \mathrm{psi}$ & $3000 \mathrm{psi}$ \\
\hline Sensor Accuracy & $+-0.25 \%$ & $+-0.25 \%$ & $+-0.5 \%$ & $+-0.5 \%$ & $+-0.5 \%$ & $+-0.5 \%$ \\
\hline
\end{tabular}




\section{TEST RESULTS}

In order to support the processes for designing a sounding rocket which was

discussed, a number of experiments were conducted. A small scale hybrid rocket motor was designed, manufactured, and statically test fired. Additionally, a small scale COPV was designed, manufactured, and hydrostatically tested to failure.

\subsection{Similarity Scaling Small Scale Test Fire}

A static test fire of the small scale hybrid rocket motor was conducted to identify any unforeseen inadequacies of the design and to gather fuel regression rate data which is critical for similarity scaling. The hybrid rocket motor was assembled on the test stand (Figure 30) and test fired. The test fire was conducted with a target chamber pressure of 2000psi, a target burn time of 2 seconds and target thrust of $600 \mathrm{lbf}$.

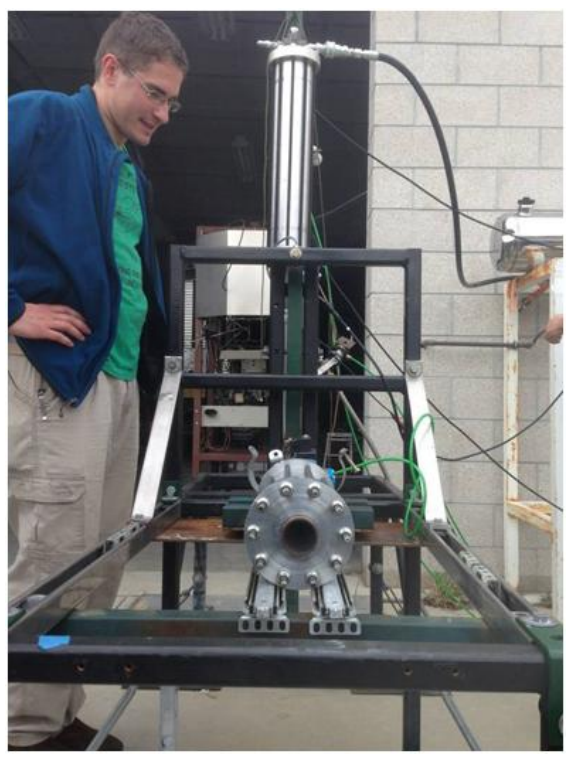

Figure 30. Small Scale Hybrid Rocket Motor on the Test Stand

During the test fire the thrust load cell measured a steady increase and subsequent decrease of thrust (Figure 31). The top of the thrust curve is a flat line because the load cell had been calibrated to measure a maximum thrust of $9691 \mathrm{bf}$ but the thrust exceeded 
this value. The thrust curve starts out near the target thrust of $6001 \mathrm{bf}$ but increases throughout the burn because of a design flaw with the nozzle. The throat of the nozzle eroded away significantly faster than expected causing a chain reaction which allowed thrust to exceed the measurement capability of the load cell. The nozzle erosion caused the chamber pressure to decease significantly. Since the mass flow rate of oxidizer through the injector is primarily dependant on the change in pressure across the injector, the mass flow rate increased significantly. The increased mass flow rate of oxidizer and resulting increase of solid fuel flow rate caused the total mass flow rate out of the nozzle to increase and the thrust of the rocket to increase significantly.

At about 1.2 seconds into the burn the thrust started to diminish rapidly; likely due to the flow through the nozzle no longer being choked at the throat and a significantly lower than intended chamber pressure at that point (Figure 32). At about 3.3 seconds all of the oxidizer was used up and significant thrust ceases. A small amount of thrust, about $37 \mathrm{lbf}$, was generated by the nitrogen used to pressurize the oxidizer flowing though the nozzle after the burning ceased.

The load cell measuring the weight of the oxidizer tank experienced significant noise during the test fire (Figure 33). The total change in tank weight could be determined from the data but not the slope of the curve which was directly correlated to the oxidizer mass flow rate. Only the average oxidizer mass flow over the entire burn could be calculated but since the mass flow rate changed significantly throughout the burn. The average oxidizer mass flow value had minimal importance.

A venturi volumetric flow meter was utilized in the oxidizer feed system in case the data from the oxidizer tank load cell was insufficient for determining oxidizer flow 
rate. Unfortunately the venturi meter also failed to adequately measure the oxidizer flow rate (Figure 34). Since the venturi meter had been made specifically for the small scale hybrid testing validation of the device was forgone. The reason for the failure of the meter to measure correctly is understood to be either because the pressure ports in the venturi being too large and causing a recirculation zone and/or the oxidizer flowed through the venturi in both liquid and solid state. Either of these problems would negate the venturi's ability to function correctly. The venturi is a volumetric flow measurement device which depends on assumptions such as incompressible flow and a constant density of the flowing medium to get mass flow rate measurements. If either or both of these assumptions are invalid for the oxidizer it easily explains the lack of effectiveness of the device.

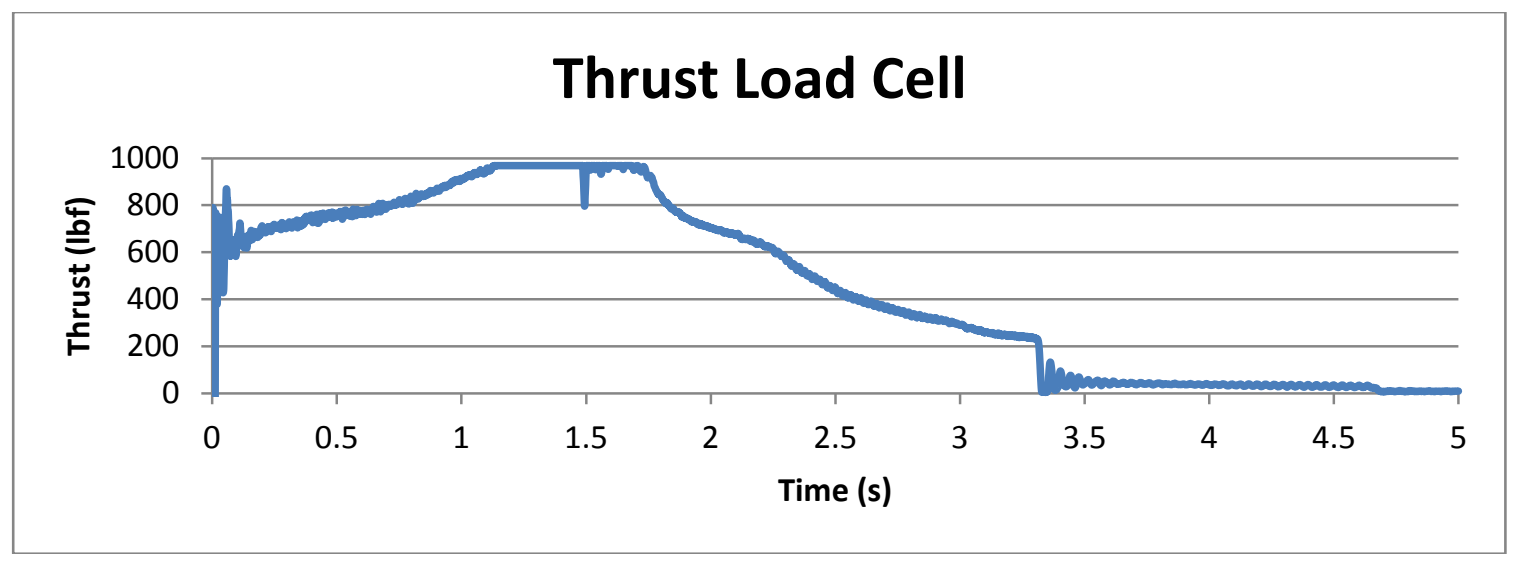

Figure 31. Small Scale Hybrid Rocket Motor Thrust Measurement 


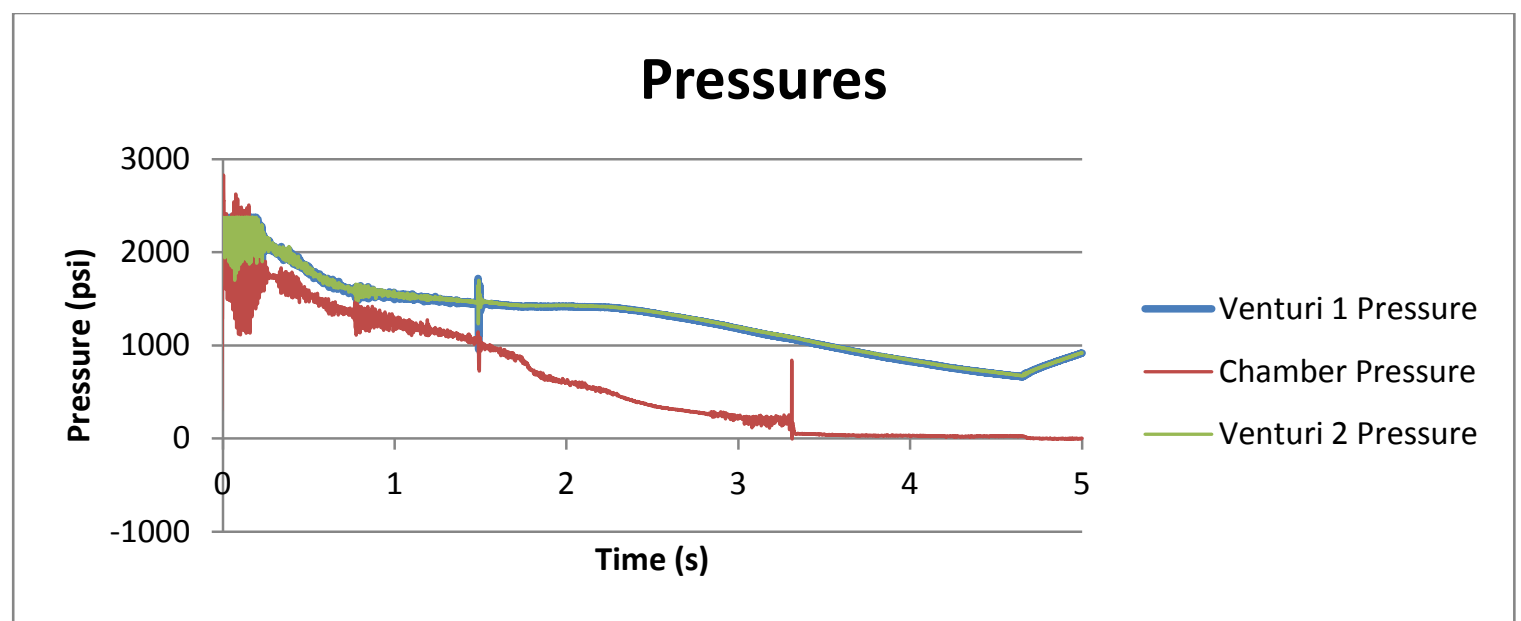

Figure 32. Small Scale Hybrid Rocket Motor Pressure Measurement

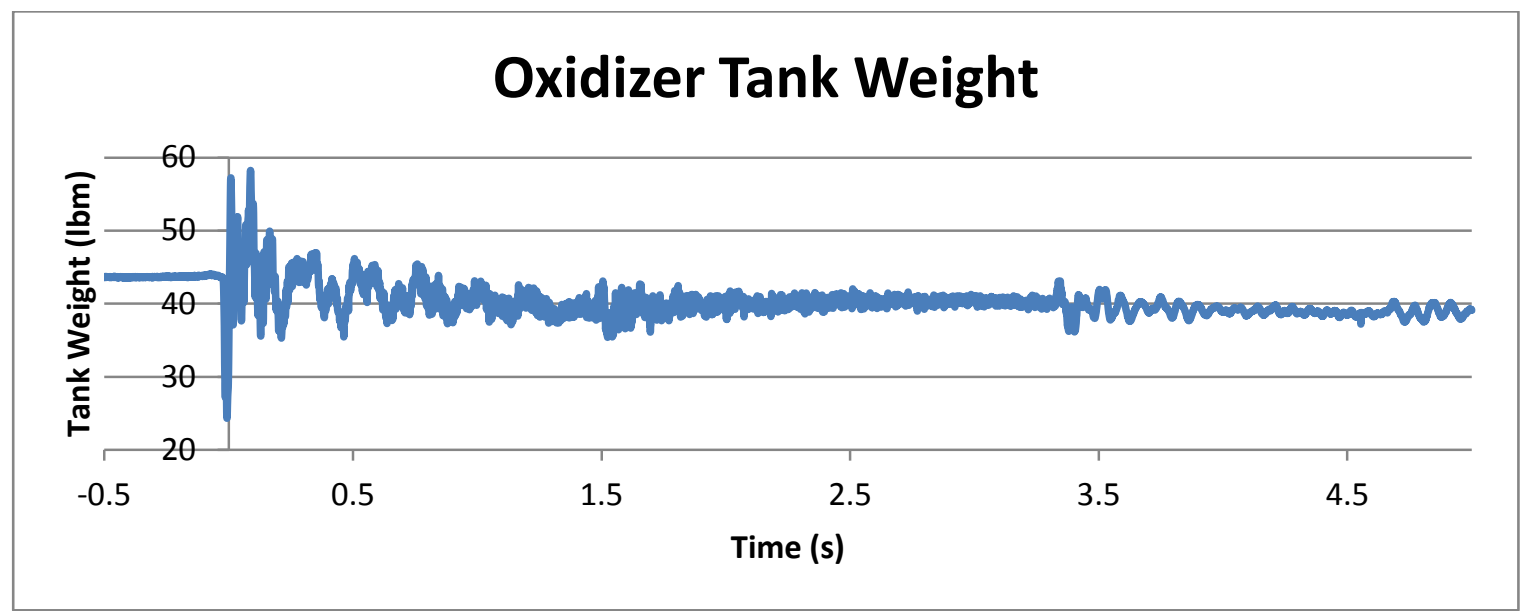

Figure 33. Small Scale Hybrid Rocket Motor Oxidizer Tank Measurement

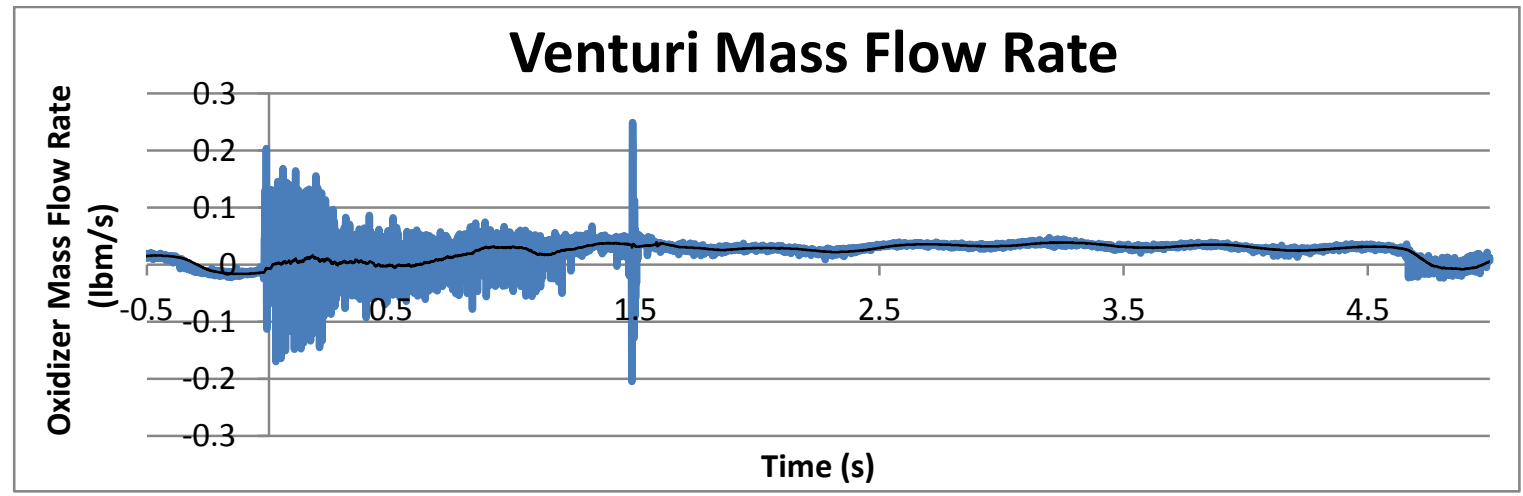

Figure 34. Small Scale Hybrid Rocket Motor Oxidizer Flow Measurement

Because of the lack of complete data from the small scale test fire accurate performance measurements were impossible. There were a number of things learned about the system which give the test significant value. The first lesson learned was that a 
high thermal mass steel nozzle was ineffective in this motor design. The throat of the nozzle started at $.47 \mathrm{"}$ and eroded to around $.9 \mathrm{n}$ in diameter over the course of the test fire (Figure 35). This failure is primarily why the test did not generate useful data. The reason that the nozzle failed in this way is due to the ambiguity in the combustion temperature during the design phase. The unknown difference between expected combustion temperature and actual combustion temperature led to the nozzle's failure. It is expected that the combustion temperature was significantly higher than anticipated for this test fire. This is yet another reason to utilize an ablative nozzle for the rocket since they have a very low regression rate even at very high temperatures, as long as the combustion gasses are fuel rich and not oxidizer rich.

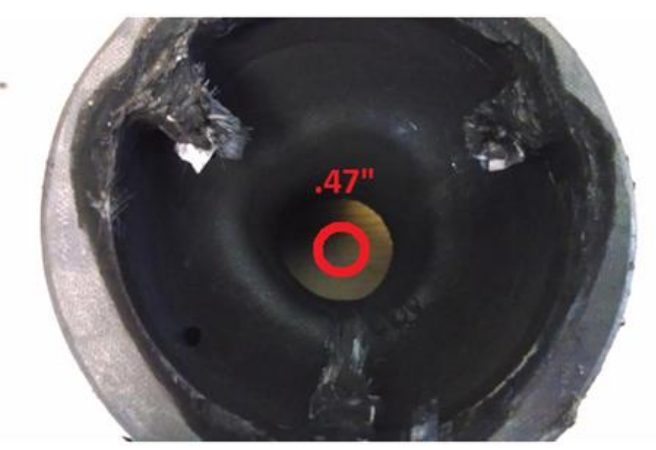

Figure 35. Small Scale Hybrid Rocket Motor Steel Nozzle After Test Fire

The injector also experienced some damage due to the high thermal loading in the combustion chamber (Figure 36). Both of the bolt heads in the center of the injector plate melted during the test and some of the injector plate near the bolt holes also melted. To solve this issue, a subsequent design removed the two central bolts. 


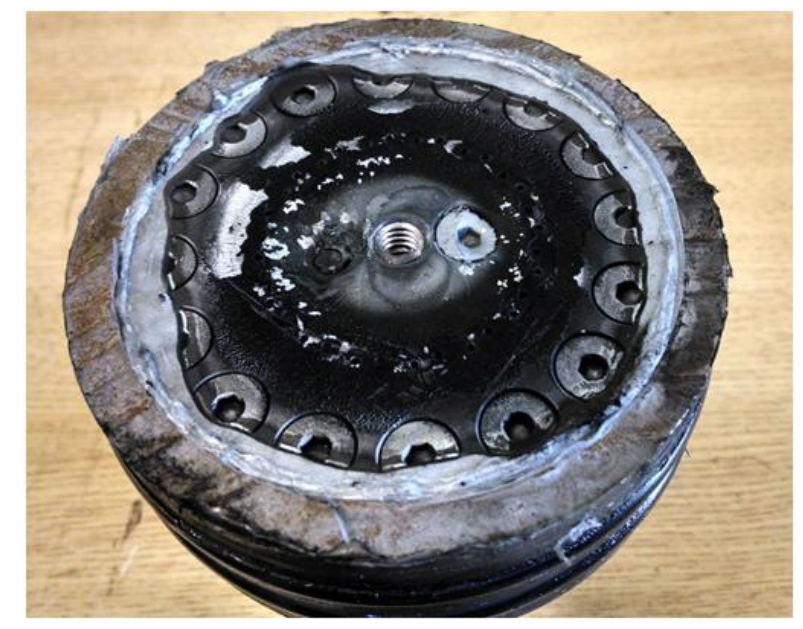

Figure 36. Small Scale Hybrid Rocket Motor Injector after Test Fire

The inner fuel grain showed good regression. However, the inner thermal liner of the grain was exposed near the injector (Figure 37). The regression of the inner fuel grain near the nozzle was approximately the anticipated amount. It was expected that the grain would regress faster near the injector where the oxidizer was being sprayed directly onto it. The outer fuel grain showed even regression down the entire fuel grain except at the surface that mated with the injector and nozzle (Figure 38). The even regression down the entire grain was likely due to the swirl injector design. It is atypical for a fuel grain to have even regression down the entire length. The high regression near the mating surfaces of the grain may have been due to heat transfer through the injector and nozzle, resulting in elevated regression at these points. Thermal barriers between the fuel grain, the nozzle, and injector may eliminate these high regression points.

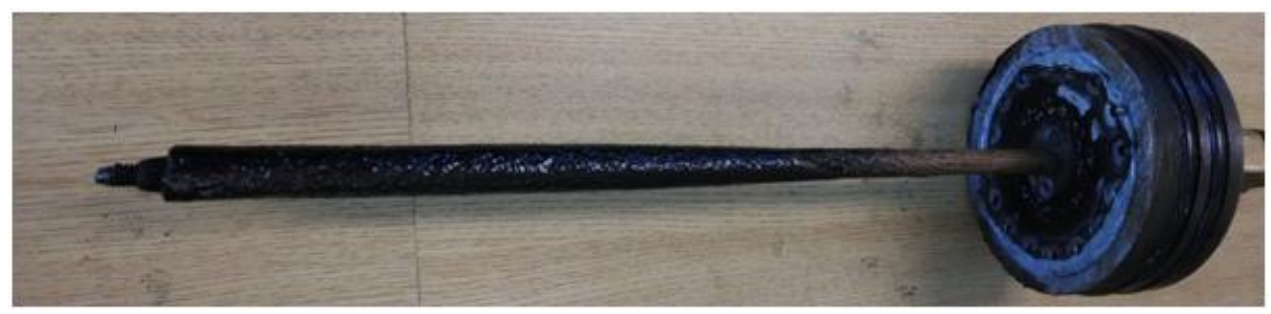

Figure 37. Small Scale Hybrid Rocket Motor Inner Fuel Grain after Test Fire 


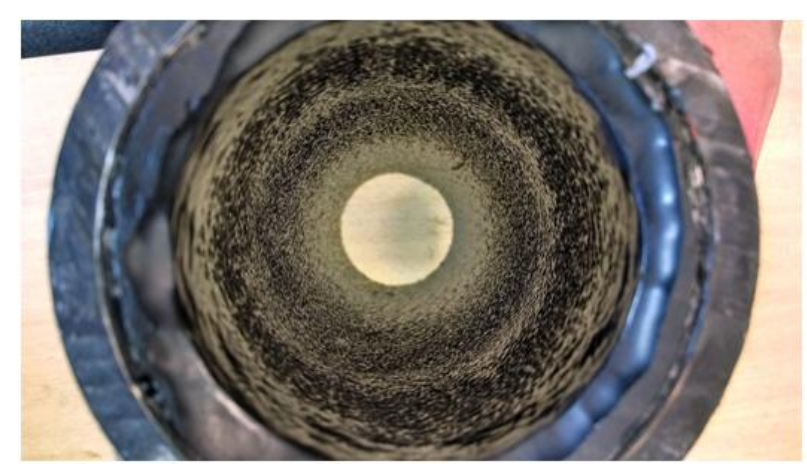

Figure 38. Small Scale Hybrid Rocket Motor Outer Fuel Grain after Test Fire

\subsection{COPV Weight Minimization Testing}

The carbon fiber tow utilized for the COPV, HexTow IM2A, was tested using ASTM D4018 to gather the tensile properties of the material (Table 8, Figure 39). It should be noted that the measured properties differ significantly from the properties published by Hexcel for this material (Table 9). The cause of the significant difference between the published and measured values has not been determined, but explanations such as incorrect labeling of the fibers have been suggested. The carbon fibers used in the experiment were received as a donation and no guarantees were made as to the quality of the product in the datasheet. The discrepancy has little impact on the study other than to be noted since the measured values were used for all calculations. 
Table 8. HexTow/West Systems Single Tow

\begin{tabular}{|cccc|} 
Specimen Label & $\begin{array}{c}\text { Max Stress } \\
(\mathrm{Ksi})\end{array}$ & $\begin{array}{c}\text { Modulus } \\
(\mathrm{Msi})\end{array}$ & $\begin{array}{c}\text { Cross Sectional Area } \\
\left(\mathrm{in}^{2}\right)\end{array}$ \\
\hline U1 & 278.5 & 16.39 & 0.00087 \\
\hline U2 & 255.7 & 15.48 & 0.00091 \\
\hline U3 & 239.9 & 16.09 & 0.00086 \\
\hline U4 & 238.7 & 16.19 & 0.00086 \\
\hline U5 & 253.6 & 17.04 & 0.00081 \\
\hline Average & 253.3 & 16.24 & \\
\hline Standard & & & \\
Deviation & 16.075 & 0.56238 & \\
\hline
\end{tabular}

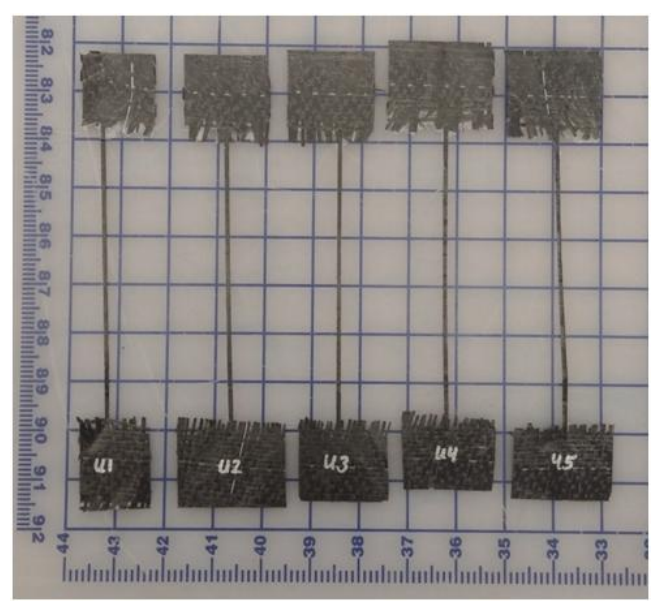

Figure 39. Single Tow Tensile Samples

Table 9. HexTow IM2A Properties Comparison

\begin{tabular}{|ccc|}
\hline & Tensile Strength (Ksi) & Tensile Modulus (Msi) \\
\hline Tested & 253.3 & 16.24 \\
\hline Published & 770 & 40 \\
\hline \% Difference & $32.9 \%$ & $40.6 \%$ \\
\hline
\end{tabular}

ASTM 2584 was followed to determine the carbon fiber and matrix mass fractions (Table 10). The mass fractions and the densities of the carbon fiber and polymer matrix were used to convert the mass fraction to volume fraction for the wrapped article (Table 11). 
Table 10. Ignition Loss Test of Angle Ply Samples

\begin{tabular}{|rr|}
\hline & Weight (grams) \\
\hline Plate & 32.8 \\
\hline Plate + samples & 55.2 \\
\hline Plate + samples after burn & 46.2 \\
\hline & \\
\hline Layup total & 22.4 \\
\hline Resin & 9 \\
\hline Fibers & 13.4 \\
\hline
\end{tabular}

Table 11. Angle Play Tensile Sample Volume Fraction

\begin{tabular}{|cl|}
\hline Fibers & Matrix \\
\hline $49.25 \%$ & $50.75 \%$ \\
\hline
\end{tabular}

To determine the properties of the angle ply, a sample of this material was wrapped and tensile tested per ASTM 3039. A sample vessel 8" in diameter was filament wound to provide the samples (Figure 40). The vessel was then sectioned (Figure 41) and cut into tensile test specimens (Figure 42) and tensile tested (Table 12).

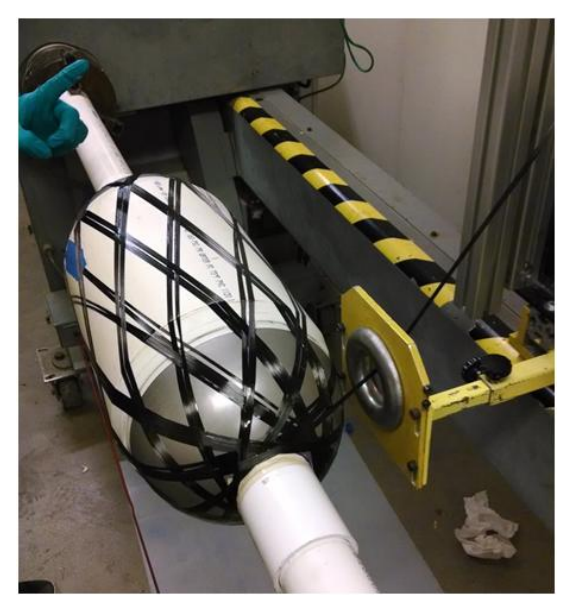

Figure 40. Sample Vessel Winding 


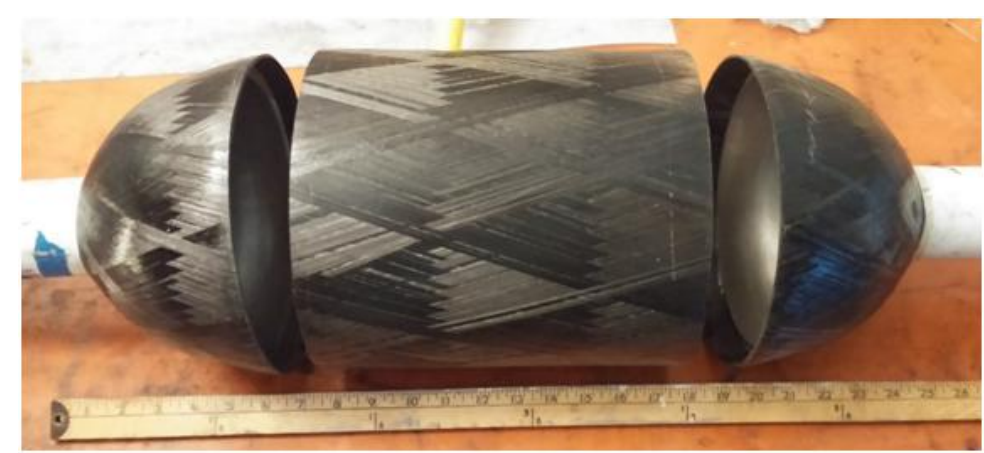

Figure 41. Sectioned Sample Vessel

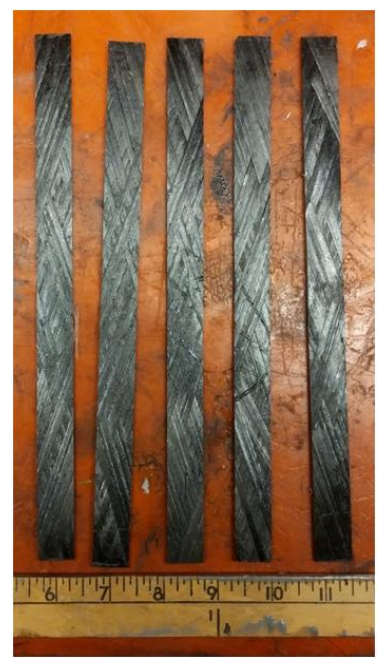

Figure 42. Sample Vessel Tensile Test Samples

Table 12. West Systems $17^{\circ}$ Angle Ply Tensile Data

\begin{tabular}{|lrrr|}
\hline Specimen Label & Max Stress (Ksi) & Modulus (Msi) & Cross Sectional Area (in^2) \\
\hline A6 & 87.5 & 9.94 & 0.05856 \\
\hline A7 & 77.2 & 11.58 & 0.05664 \\
\hline A8 & 81.3 & 11.88 & 0.0534 \\
\hline A9 & 71.9 & 11.77 & 0.05846 \\
\hline Average & 79.5 & 11.30 & \\
\hline
\end{tabular}

To investigate the properties of a COPV useful for a rocket, a small scale pressure vessel was wrapped (Figure 43). The vessel was instrumented with pressure transducers and strain gauges (Figure 44) and hydrostatically tested to failure (Figure 45). The maximum stress that the vessel was able to withstand was only slightly lower than the predicted value using CLT. However, the predicted strain was about 4 times lower than 
measured (Table 13). This may have been due to poor consolidation of the laminas since they were not vacuum bagged to remove voids. The epoxy matrix could have failed and allowed the fibers to shift during pressurization which may explain the elevated strain values from the test. In the geometry after the matrix failure the stress would have been distributed using Netting Theory which explains why the composite could still hold the expected pressure even though it exhibited excessive strain.

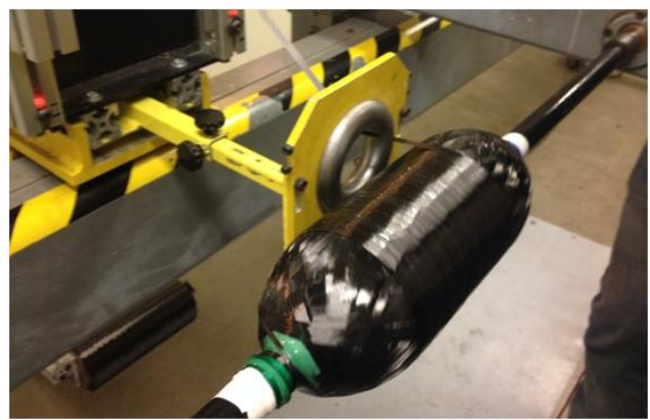

Figure 43. Vessel Winding
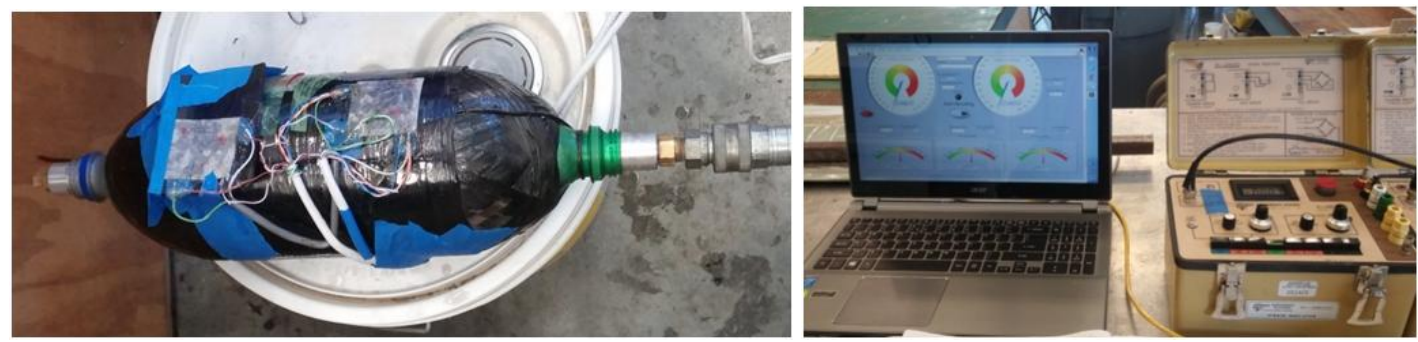

Figure 44. Hydrostatic Test Instrumentation

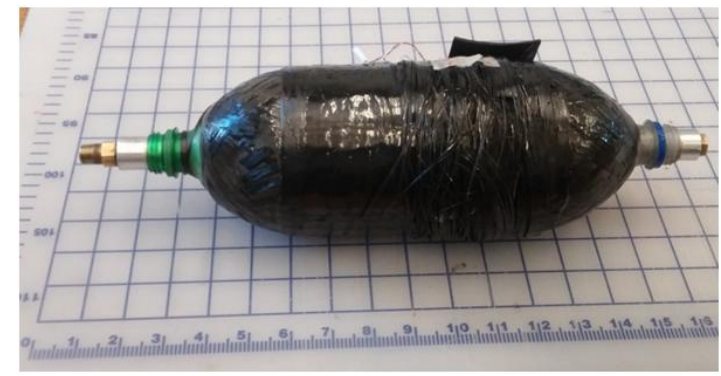

Figure 45. Post Burst Test

Table 13. Vessel Layup Properties

\begin{tabular}{|llllll|} 
Ksi & $\delta_{\mathrm{x}}$ & $\delta_{\mathrm{y}}$ & $\mathrm{E}_{\mathrm{x}}$ & $\mathrm{E}_{\mathrm{y}}$ & $\mathrm{G}_{\mathrm{xy}}$ \\
\hline Calculated & 180.3 & 32.46 & 8511 & 4583 & 3517 \\
\hline Measured & 171 & 30.8 & 51591 & 15009 & 18153 \\
\hline \% Difference & $5 \%$ & $5 \%$ & $84 \%$ & $69 \%$ & $81 \%$ \\
\hline
\end{tabular}




\section{CONCLUSION}

This study has endeavored to provide insights for successful scaling of a hybrid powered sounding rocket. The intent has been to provide others who are interested in developing a hybrid sounding rocket a basis for understanding and implementing their project. The project was not able to include the full scale portion of the work due to logistical limitations but has illustrated beneficial tactics and method for the small scale portion. The small scale portion of the similarity scaling was tested and a number of areas that need improvement were identified. Preliminary investigations into weight minimization of some rocket structures including a pressurized tank and an ablative nozzle have been presented. A prototype COPV was manufactured and tested with success. An ablative nozzle was manufactured and met visual inspection criteria but structural and thermal tests were not conducted.

\subsection{Similarity Scaling}

Similarity scaling has shown significant promise for successful scaling of hybrid rocket motors. This study has identified challenges to the design and manufacturing process which are important to note. A challenge of similarity scaling are the limitations on how different two motors can be while maintaining similarity. Another challenge with scaling is the testing itself and how daunting unexpected hindrances can be. It is the challenges that aren't expected that set back a development schedule the most. The testing revealed that the injector swirling caused near even regression of the outer fuel grain which is excellent. However, the steel injector and nozzle were not sufficient for the thermal loading in the combustion chamber and both exhibited erosion. Continued work on small scale testing should allow for a relatively low difficulty scale up to a sounding rocket propulsion system once the all the subsystems perform sufficiently. A study which 
developed multiple larger scale motors and accurately predicted their performance would be of benefit in supporting this work.

\subsection{Weight Minimization}

It was shown that utilizing rather simplistic analysis, a COPV could be designed

for use in small scale testing. A small scale COPV satisfactory for testing would have had a mass fraction of $58 \%$ while a similar heavy weight metallic pressure vessel had a mass fraction of $85 \%$. The weight saving between these two design methodologies is $27 \%$ for the small scale testing in this work. While neither design was optimized for weight, the COPV inherently had a significant advantage in weight due to the manufacturing process. This difference at the small scale is a bit of a misnomer since the structural efficiency of a vessel increases with size. The mass fractions of both a COPV and a heavy weight metallic vessel would be significantly higher for a full scale vessel. The creation of a full scale tank for a sounding rocket is suggested to further this work and gain more accurate comparisons.

This same COPV manufacturing and analysis method could also be utilized in a full scale flight motor for both the oxidizer tank and the combustion chamber. This would lead to a significant weight savings over traditional light weight metallic construction. A composite ablative nozzle could also be filament wound and could even be made continuous with a filament wound combustion chamber, thus eliminating fasteners and further reducing weight. The injector design discussed could be scaled with the combustion chamber and perform well in a full scale sounding rocket propulsion system. These technologies could assist in the development of a SSTO launch vehicle. 


\section{REFERENCES}

1. Karabeyoglu, Arif, Hybrid Rocket Propulsion for Future Space Launch [PDF document]. May 9, 2008. Retrieved from https://aa.stanford.edu/events/50thAnniversary/media/Karabeyoglu.pdf

2. Estey, P., D. Altman, J. McFarlane, "An evaluation of scaling effects for hybrid rocket motors." AIAA-91-2517, 27th AIAA Joint Propulsion Conference, Sacramento, CA, June 1991.

3. Merkle, C., S. Venkateswaran, "Size scale-up in hybrid rocket motors," AIAA 34th Aerospace Sciences Meeting and Exhibit, Reno, NV Jan 1996.

4. Gany, Alon, "Scale effects in hybrid motors under similarity conditions," AIAA-962846, 32th AIAA Joint Propulsion Conference, Lake Buena Vista, FL, July 1996.

5. Swami, Rajeshwar Dayal, Alon Gany, "Analysis and testing of similarity and scale effects in hybrid rocket motors," Acta Astronautica 52 (2003), pg. 619 - 628.

6. Cai, Guobiao, Peng Zeng, Xintian Li, Hui Tian, Nanjia Yu, "Scale effect of fuel regression rate in hybrid rocket motor," Aerospace Science and Technology 24 (2013) 141-146.

7. Shan, Fanli, Lingyun Hou, Ying Piao, "Combustion, performance, and scale effect from N2O/HTPB hybrid rocket motor simulations.” AIAA-91-2517, 27th AIAA Joint Propulsion Conference, Sacramento, CA, June 1991.

8. Swanson, S.R., Introduction to Design and Analysis with Advanced Composite Materials, Upper Saddle River, NJ: Prentice Hall, 1997.

9. Arena, Zach, Alexander Athougies, Alden Rodulfo, "Hybrid Rocket Motor," Senior project, California Polytechnic State University San Luis Obispo, 2010.

10. Park, Jong Kyoo, Tae Jin Kang, "Thermal and ablative properties of low temperature carbon fiber-phenol formaldehyde resin composites," Carbon, Volume 40, Issue 12, 2002, Pages 2125-2134.

11. Walrath, Stephen, "Hybrid Rocket Motor Test Stand," Senior project, California Polytechnic State University San Luis Obispo, 2006. Microform. 
Appendix A. HaRMleSS Static Test Fire Procedures

Procedures for Hybrid Rocket Motor Similarity Scaling Thesis Project (HaRMleSS) Static Test Firing

Purpose: This procedure enables the safe static test firing of hybrid rocket motors.

Description: The process for inspecting components, setting up test systems, pre-fire checks, test firing and post-firing inspection are all included in this document. This HaRMleSS Procedure contains a safe progression of steps for completing the aforementioned tasks and as such should be followed astutely to ensure nominal testing results.

Only the advisor can approve any "redline" changes to the test procedure.

Roles and Responsibilities

\begin{tabular}{|c|c|c|}
\hline Role & Responsibilities & Name(s) \\
\hline \multirow{5}{*}{ Test Conductor (TC) } & Leader of the test activities & \multirow{5}{*}{ Joseph Vanherweg } \\
\hline & $\begin{array}{l}\text { Assures that all precautions cited in } \\
\text { the test procedure are implemented }\end{array}$ & \\
\hline & $\begin{array}{l}\text { Assumes responsibilities for all the } \\
\text { quality control issues that arise } \\
\text { during the test }\end{array}$ & \\
\hline & $\begin{array}{l}\text { Leads the pre-test briefing, if } \\
\text { applicable, and, before starting, } \\
\text { reviews the test procedure with all } \\
\text { the participants }\end{array}$ & \\
\hline & $\begin{array}{l}\text { Maintains position of command and } \\
\text { control during firing }\end{array}$ & \\
\hline \multirow{3}{*}{ Safety Control (SC) } & $\begin{array}{l}\text { Assumes overall system safety } \\
\text { responsibility during the test }\end{array}$ & \\
\hline & $\begin{array}{l}\text { Assures that all the required safe } \\
\text { practices are implemented during } \\
\text { the test procedure and that } \\
\text { operations are performed in the } \\
\text { proper order }\end{array}$ & \\
\hline & $\begin{array}{l}\text { Operates fire extinguisher in case of } \\
\text { fire during test. }\end{array}$ & \\
\hline \multirow{2}{*}{$\begin{array}{l}\text { Fire and Sensor Control } \\
\text { (FSC) }\end{array}$} & $\begin{array}{l}\text { Operates all actuated disconnects } \\
\text { and firing valves as well as the } \\
\text { ignition circuit }\end{array}$ & \\
\hline & $\begin{array}{l}\text { Will shut off all control circuits in } \\
\text { the event of an abort }\end{array}$ & \\
\hline
\end{tabular}




\begin{tabular}{|l|l|l|}
\hline Role & Responsibilities & Name(s) \\
\hline & $\begin{array}{l}\text { In charge of all sensors and data } \\
\text { acquisition during the test as well as } \\
\text { filling and venting operations. }\end{array}$ & \\
\cline { 2 - 2 } & $\begin{array}{l}\text { Stands watch at predetermined } \\
\text { positions to prevent bystanders from } \\
\text { approaching the test area }\end{array}$ & \\
\hline \multirow{2}{*}{$\begin{array}{l}\text { Range Safety } \\
\text { (multiple) }\end{array}$} & $\begin{array}{l}\text { Will have radio communication to } \\
\text { Test Control }\end{array}$ & \\
\cline { 2 - 3 } & & \\
\hline
\end{tabular}

\section{Safety Callouts and PPE}

Initial Safety Callouts (To be read out loud before beginning the procedure)

1. At no point in time during this procedure will a participant enter the test cell while nitrous oxide is flowing or is being pressurized.

2. Everyone present is encouraged to have a questioning attitude, and should be on the lookout for potential hazards. Everyone present has the responsibility to call an all-stop in the event that he or she perceives something as unsafe.

3. The test stand can only be approached when the pressure in the system is less than $1 / 4$ the burst pressure of the system and when no liquids or gasses are flowing in the system. At no point during 3.3 Fill Procedure and 3.4 Fire Procedure should anyone place any part of their body in from of or near the nozzle of the rocket motor.

\section{Personal Protective Equipment}

1. All participants are required to wear ear plugs or ear muffs during section 3.4 (Fire Procedure).

2. All participants must wear long pants and close toed shoes.

3. All participants must wear safety glasses during this procedure when working on or around equipment.

4. The conductor must wear a face shield when in close proximity to the launch trailer or test stand. (He or she will only be near the test stand when the procedures require that he or she be near the test stand).

\section{PRE-NITROGEN PURGE}

\section{Procedure Activities}

1. Verify V1 is closed

2. Verify V3 is open

3. Open $\mathrm{N}_{2}$ ball valve $\mathrm{V} 4$

4. Connect regulator to $\mathrm{N}_{2}$ bottle

5. Open tank valve and adjust regulator to 100psi

6. Open Fill valve until pressure stabilizes

7. Open vent valve for 10 seconds and close

8. Close Fill valve 
9. Manually close $\mathrm{N}_{2}$ tank valve

10. Close V4

11. Open V1

\section{PRE-IGNITION CHECKLIST}

1. Trailer 12-Volt battery that is located in the Fore Box is charged and connected

2. Computer with LabVIEW running

3. Computer connected to Data Acquisition System

4. All relevant instruments connected and reading

5. GO-PRO/cameras(s) set up with memory card

6. Trailer connected to air supply @ 90psi

7. Fill valve activation

8. Dump valve activation

9. Vent solenoid operation

10. Fill quick disconnect operation

11. Vent quick disconnect operation

12. Verify disconnects should not interfere with pressure transducers

13. Fire valve operation

\section{FILL PROCEDURE}

1. Connect NOX-H1 to $\mathrm{N}_{2} \mathrm{O}$ tank

2. Verify V3 is open

3. Range safety personnel in position

4. Clear test area. Test is now live. Authorized personnel only allowed within test area.

5. Open $\mathrm{N}_{2} \mathrm{O}$ tank valve

6. Hold tank weight in LabVIEW

7. Turn on GO-PRO(s)

8. Open Fill valve

9. Open Vent valve periodically to maintain pressure by venting system when pressure is above 750psi

10. Close Fill valve when delta tank weight readout is the desired amount of nitrous in pounds. Note: $0.2 \mathrm{lb}$ of $\mathrm{N}_{2} \mathrm{O}$ in Fill Line

11. Disconnect Vent assembly (only for high pressure super charged test)

12. Disconnect Fill assembly

Fire Procedure: this section will be read aloud before proceeding to ensure everyone present understand what will occur.

1. Attach igniter leads

i. Touch igniter leads together to ground before connecting

2. Attach high pressure hose to N2 cylinder on the trailer

3. Verify range safety and data collection

4. Begin LabVIEW documentation

5. Ear and Eye Protection 
6. Begin Countdown

i. If broadcast over radio make sure to release button with approximately 5 seconds left in countdown in case of need to stop countdown

7. Ignition start

8. Close Tanks

9. Open Dump Valve

10. Open Fill Valve

11. Open Fire Valve

12. Close Fill Valve

13. Close Dump Valve

Note: The test cell is now safe and range safety can be recalled.

Post-Fire N2 Purge

\section{Post Fire-Procedure Activities}

1. Verify V1 is closed

2. Verify $\mathrm{V} 3$ is open

3. Open $\mathrm{N}_{2}$ ball valve V4

4. Open Fill valve until pressure stabilizes

5. Open Dump Valve for 3 seconds

6. Close Fill valve

7. Manually close $\mathrm{N}_{2}$ tank valve

8. Disconnect NOX-H1 from nitrous tank

9. Open V1, be aware of venting gas

10. Close V4 and V1

11. Disconnect fittings from all high pressure cylinders and replace safety caps.

\section{Off-nominal conditions Procedures}

Note: The test cell can only be entered when the pressure in the system is less than $1 / 4$ the burst pressure and when no liquids or gasses are flowing in the system. At no point between 3.3 Fill Procedure and 3.4 Fire Procedure should anyone place any part of their body in from of or near the nozzle.

Failure to Ignite

1. Ensure firing circuit is armed

2. Disable fire valve circuit

3. Check continuity on igniter from relay and work through system to igniter

4. If continuity check finds no faults, disconnect ignition leads and ensure correct functioning of fire circuitry

5. If no problems detected a new igniter must be placed in motor, consult advisor for safe plan of action in this scenario

$\mathrm{N}_{2} \mathrm{O}$ Fire Valve Failure After Ignition Grain Activation

1. Reattempt opening of fire valve

2. Disable fire valve circuit 
3. Check wiring in the test cell control room and on the trailer

4. Ensure sufficient air pressure to fire valve actuator

5. Close $\mathrm{N} 2$ cylinder valve

6. Vent NOX-H1

7. Lower pressure in $\mathrm{N} 2 \mathrm{O}$ tank by venting using the $\mathrm{N} 2$ manual vent valve for a short time and attempt to reattach $\mathrm{NOX}-\mathrm{H} 1$ to $\mathrm{N} 2 \mathrm{O}$ tank while pressure is lowered

8. Check wiring from control box to fire valve, LED on actuator solenoid will light up if wiring is correct (disconnect air pressure to ensure no actuation during check)

9. Utilize the $\mathrm{N} 2 \mathrm{O}$ Dump valve to empty $\mathrm{N} 2 \mathrm{O}$ tank

10. Proceed to 6.1 Post Fire N2 Purge

11. Troubleshoot fire valve as necessary

Significant $\mathrm{N}_{2} \mathrm{O}$ Leak

1. Depressurize leaking line/vessel using appropriate vent

2. Disassemble leaking connection and inspect for cause of leak

3. Reassemble connection, ensure to torque to appropriate specification

Catastrophic Failure

1. Immediately shut any open valves in the $\mathrm{N} 2 \mathrm{O}$ systems starting with the remotely actuated valves

2. Locate fire extinguisher

3. Seek guidance from Advisor and/or other R.P.

\section{Troubleshooting}

In the event that an off-nominal condition occurs that prevents continuation of the procedures but is not covered in Section 0, the following troubleshooting procedures shall be followed.

1. De-energize any electrical control circuits via safety switches

2. Identify sources of off-nominal condition

3. Disconnect connectors to ignition charge if connected

4. Depressurize N2O tank if appropriate

5. If source is electrical, check electrical connects with a multimeter

6. When problem is resolved the procedures may be restarted

\section{Approval}

Date:

Date:
Advisor: Dr. Dianne DeTurris

Additional Signoff: 
Appendix B. COPV Hydrostatic Test Procedures

Last Updated: 8 May 2014

Safety Notes: Personal protective equipment (PPE) must be worn by all persons who are taking part in testing. PPE for a standard test include safety glasses, long pants, and close toes shoes. If a test article must be approached, it must be bled to a low pressure before being approached.

1. Calibrated all test equipment prior to first hydrostatic test

2. Record the bottle data, including: test number, manufacturers date, serial number, manufacturer, size of bottle, and pre-determined test pressure (test pressure is typically $5 / 3$ operating pressure).

3. Perform internal/external inspection per the inspection criteria specified in the standards that follow.

4. Fill the test article (bottle) with water of the same temperature as is in the test reservoir (ensure the test article is complete full, no gas inside), affix the correct quick disconnect fitting to the bottle.

5. Attach the bottle to the quick disconnect fitting located on the hydrostatic test station's hose.

6. Fill test reservoir with water and submerge the bottle into the reservoir until under six or more inches $(+6 ")$ of water.

7. Turn on the water supply to the hydrostatic pump and fill the hose to the bottle with water.

8. Pressurize bottle to the test pressure and hold for a minimum of 30 seconds. Record strain at end of 30 seconds.

9. Shut off the water supply and bleed the pressure off the bottle.

10. Record the permanent strain. The total strain $\left(\varepsilon_{\text {total }}\right)$ minus the permanent strain $\left(\varepsilon_{\text {permanent }}\right)$ gives you the elastic strain $\left(\varepsilon_{\text {total }}-\varepsilon_{\text {permanent }}=\varepsilon_{\text {elastic }}\right)$.

11. Determine the percent of permanent strain, divide the permanent strain by the total strain.

12. Record if the bottle passed or failed.

13. Stamp or sticker the bottle with the hydrostatic test date.

14. Drain the remaining water from the system and disassemble as necessary.

DOT FRP1

\section{Standards Referenced:}

DOT CFFC

ISO 11119-2

ISO 11119-3

CSA B51 Part 2 


\section{Appendix C. Similarity Motor Design Code}

1. clc

2. clear

3.

4. \%Joseph Vanherweg

5. \%HM6 Similarity Design Code

6. \%Started on $10 / 11 / 13$

7. \%Finished on $12 / 30 / 13$

8. \%Inputs

9.

10. F2= 2000; \% Major Thrust Desired, lbf

11. F1= 550; \% mini Thrust Desired, lbf

12. $\mathrm{tb} 2=26$; \% Major Burn Time, seconds

13. $\mathrm{tb} 1=2 ; \%$ mini Burn Time, seconds

14.

15. deltarc2=.75; \% major difference in radius between inner grain outer radius and outer grain inner radius, in

16. deltarc1=.25; \% mini difference in radius between inner grain outer radius and outer grain inner radius, in

17. $\operatorname{rdot} 1=.1545 ; \%$ mini fuel linear regression rate, in/s

18. $\mathrm{rs} 2=1 ; \%$ Major grain centering rod radius, in

19. $r s 1=.1875 ; \%$ Minor grain centering rod radius, in

20.

21. $\mathrm{q} 2=0.3$; \%rin2 adjustment variable, in

22. $\mathrm{Q} 2=0.3$; \% rou 2 adjustment variable, in

23. Q1=0.251; \%rou1 adjustment variable, in

24. FMi=1.2; \% Factor of Safety, for burn parameters on inner grain

25. $\mathrm{FMo}=1.2 ; \%$ Factor of Safety, for burn parameters on outer grain

26.

27. $\operatorname{tankr2}=5 ; \%$ nitrous tank radius, in

28. Ninj=32; \% Injector hole \#

29. $\mathrm{Cd} 2=.8 ; \%$ Flow coefficient for injectors

30. $\mathrm{Cd} 1=.82$; \% Flow coefficient for injectors

31.

32. pc $2=550 ; \%$ Major chamber pressure, psi

33. deltaPinj=250; \% dP over injector, psi

34. $\mathrm{Cf}=1.55$; \% thrust coefficient

35. P3=11.3; \% Pressure at Design Altitude(7000 ft), psi

36. Isp $=190 ; \%$ expected Specific Impulse, seconds

37. $\mathrm{OF}=4.5 ; \%$ Oxidizer to Fuel Ratio, $\mathrm{O} / \mathrm{F}$

38. rhof=.033; \% fuel density, lb/in^3

39. rhoN2O=46.48; \%liquid $\mathrm{N} 2 \mathrm{O}$ density, $\mathrm{lb} / \mathrm{ft}^{\wedge} 3$

40.

41. \% Constants

42.

43. $\mathrm{pi}=3.14159$; 
44. $\mathrm{g}=32.1742 ; \%$ gravity, $\mathrm{ft} / \mathrm{s}^{\wedge} 2$

45. $\mathrm{FoS}=3$; \% Factor of Safety, for structural parameters

46.

47. \% HM6

48.

49. Mdot2=F2/Isp; $\%$ total mass flow, $1 \mathrm{bm} / \mathrm{s}$

50. $\operatorname{mdotf} 2=\mathrm{Mdot} 2 /(\mathrm{OF}+1) ; \%$ mass flow of fuel, $1 \mathrm{bm} / \mathrm{s}$

51. $\operatorname{mdotox} 2=\mathrm{OF} * \operatorname{Mdot} 2 /(\mathrm{OF}+1) ; \%$ mass flow of oxidizer, $1 \mathrm{bm} / \mathrm{s}$

52.

53. $\operatorname{rdot} 2=\operatorname{rdot} 1 * \mathrm{~F} 1 / \mathrm{F} 2 ; \%$ fuel regression rate, in/s

54.

55. rin $2=\mathrm{rs} 2+\mathrm{tb} 2 * \mathrm{rdot} 2 * \mathrm{FMi}+\mathrm{q} 2 ; \%$ Major inner grain initial outer radius, in

56. rou $2=$ rin $2+$ deltarc $2+$ rdot $2 *$ tb $2 * \mathrm{FMo}+\mathrm{Q} 2$; \%outer grain outer radius, in

57.

58. A2o $=$ pi* $(\text { deltarc2+rin2 })^{\wedge} 2$-pi*rin $2^{\wedge} 2$; \%initial combustion chamber area, in ${ }^{\wedge} 2$

59. $\mathrm{A} 2 \mathrm{f}=\mathrm{pi}^{*}(\operatorname{deltarc} 2+\operatorname{rin} 2+\mathrm{tb} 2 * \operatorname{rdot} 2)^{\wedge} 2-\mathrm{pi} *(\operatorname{rin} 2-\mathrm{tb} 2 * \operatorname{rdot} 2)^{\wedge} 2 ; \%$ final combustion chamber area, in^2

60. $\mathrm{Abar} 2=(\mathrm{A} 2 \mathrm{o}+\mathrm{A} 2 \mathrm{f}) / 2 ; \%$ average combustion chamber area, in^2

61.

62. Gox $2=$ mdotox $2 / A b a r 2 ; \%$ Major oxidizer mass flux, $1 \mathrm{~b} / \mathrm{in}^{\wedge} 2 / \mathrm{s}$

63. Gf2=rhof*. $1735^{*}$ Gox $2^{\wedge} .7415 ; \%$ Major fuel mass flux, lb/in^2/s

64. As2 $=$ mdotf2/Gf2; \% Major fuel grain surface area, in^2

65. Lc2 $=$ As2 $/((2 *$ rin $2+$ deltarc2 $) * 2 *$ pi); \%chamber length, in

66.

67. rin2f=rin2-tb2*rdot2; \%inner chamber radius after burn, in

68. deltarc $2 \mathrm{f}=$ deltarc $2+2 * \operatorname{tb} 2 * \operatorname{rdot} 2 ; \%$ outer chamber radius after burn, in

69. rinr2=rin2f-rs2; \%inner chamber left after burn, in

70. rour2=rou2-rin2f-deltarc2f; \%outer chamber left after burn, in

71.

72. massox $2=$ mdotox $2 * \mathrm{tb} 2 ; \%$ mass of oxidizer needed, $1 \mathrm{bm}$

73. massf $2=$ rhof $* \mathrm{pi}^{*} \mathrm{Lc} 2^{*}\left(\operatorname{rou} 2^{\wedge} 2-\operatorname{rs} 2^{\wedge} 2-(\operatorname{rin} 2+\operatorname{deltarc} 2)^{\wedge} 2+\operatorname{rin} 2^{\wedge} 2\right) ; \%$ mass of fuel grain, $\mathrm{lbm}$

74. Massf $2=\operatorname{rhof}^{*} \mathrm{pi}^{*} \operatorname{Lc} 2^{*}\left((\operatorname{rin} 2 \mathrm{f}+\operatorname{deltarc} 2 \mathrm{f})^{\wedge} 2-(\operatorname{rin} 2+\operatorname{deltarc} 2)^{\wedge} 2+\operatorname{rin} 2^{\wedge} 2-\operatorname{rin} 2 \mathrm{f}^{\wedge} 2\right)$; $\%$ mass of fuel burned, lbm

75. Itot2=tb2*F2; \% Total Impulse, lb*s

76.

77. $\operatorname{rinj} 2=$ rin $2+$ deltarc $2 / 2 ; \%$ center radius of injector circle, in

78.

79. rv2=(rin2-rs2)/3+deltarc $2 / 2$; \%radius of vortex outlet, in

80. Ninj2 $=2 *$ pi*rinj2/rv2; \% number of injector vortices

81.

82. At $2=\mathrm{F} 2 /(\mathrm{Cf} * \mathrm{pc} 2) ; \%$ throat area , in^2

83. $\mathrm{Rt} 2=\operatorname{sqrt}(\mathrm{At} 2 / \mathrm{pi}) ; \%$ throat radius, in

84. 
85. Rinj2=sqrt $\left(\right.$ mdotox $2 /\left(\mathrm{Cd} 2 * \mathrm{Ninj}^{*} \mathrm{pi}^{*} \operatorname{sqrt}(2 *\right.$ rhoN2O*deltaPinj*g/144) $\left.)\right)$; \% injector hole radius, in

86. $\operatorname{tankv} 2=\operatorname{massox} 2 / \mathrm{rhoN} 2 \mathrm{O}^{*} 12^{\wedge} 3 ; \%$ nitrous tank volume, in^3

87. $\operatorname{tank1} 2=\left(\operatorname{tankv} 2-2 / 3 * \mathrm{pi}^{*} \operatorname{tankr} 2^{\wedge} 3\right) / \mathrm{pi} / \operatorname{tankr} 2^{\wedge} 2+2 * \operatorname{tankr} 2 ; \%$ nitrous tank volume, in^3

88.

89. \%HM5.6

90.

91. Mdot1=F1/Isp; \% total mass flow, lb/s

92. $\operatorname{mdotf} 1=\mathrm{Mdot} 1 /(\mathrm{OF}+1) ; \%$ mass flow of fuel, $1 \mathrm{~b} / \mathrm{s}$

93. $\operatorname{mdotox} 1=\mathrm{OF} * \mathrm{Mdot} 1 /(\mathrm{OF}+1) ; \%$ mass flow of oxidizer, $1 \mathrm{~b} / \mathrm{s}$

94.

95. Abar1=Abar2*(Mdot1/Mdot2 $)^{\wedge} 2 ; \%$ average combustion chamber area, in^2

96. Gox $1=$ mdotox $1 /$ Abar1; \%Major oxidizer mass flux, $1 \mathrm{~b} / \mathrm{in}^{\wedge} 2 / \mathrm{s}$

97. rdotex $1=.1645^{*} \operatorname{Gox} 1 \wedge .5688 ; \%$ what the rdot should be, in $/ \mathrm{s}$

98. Gf1=rhof*rdot1; \%Major fuel mass flux, $1 \mathrm{~b} / \mathrm{in}^{\wedge} 2 / \mathrm{s}$

99. As1=mdotf1/Gf1; \% Major fuel grain surface area, in^2

100. pc $1=$ pc $2 *$ sqrt(Abar2/Abar1); \% mini chamber pressure, psi

101.

102. $\operatorname{rin} 1=($ Abar1-pi*deltarc $1 *(\operatorname{rdot} 1 * \operatorname{tb} 1+\operatorname{deltarc} 1)) /(2 * \mathrm{pi} *(\operatorname{rdot} 1 * \operatorname{tb} 1+\operatorname{deltarc} 1))$;

$\%$ mini inner grain initial outer radius, in

103. $\operatorname{rin} 1 \mathrm{n}=\mathrm{rs} 1+\mathrm{tb} 1 * \mathrm{rdot} 1 * \mathrm{FMi} ; \%$ mini inner grain initial outer radius required, in

104. rou1=rin1+deltarc1+rdot $1 *$ tb $1 *$ FMo+Q1; \%outer grain outer radius, in

105. $\mathrm{A} 1 \mathrm{o}=\mathrm{pi} *(\text { deltarc } 1+\mathrm{rin} 1)^{\wedge} 2-\mathrm{pi}^{*} \mathrm{rin} 1^{\wedge} 2$; \% initial combustion chamber area, in 2

106. A1f $=\mathrm{pi}^{*}(\text { deltarc } 1+\mathrm{rin} 1+\mathrm{tb} 1 * \operatorname{rdot} 1)^{\wedge} 2-\mathrm{pi}^{*}(\operatorname{rin} 1-\mathrm{tb} 1 * \mathrm{rdot} 1)^{\wedge} 2$; \% final combustion chamber area, in^2

107.

108. Lc1=As1/((2*rin1+deltarc1)*2*pi); \%chamber length, in

109.

110. rin $1 \mathrm{f}=$ rin $1-\mathrm{tb} 1 * \mathrm{rdot} 1 ; \%$ inner chamber radius after burn, in

111. deltarc $1 \mathrm{f}=$ deltarc $1+2 *$ tb $1 *$ rdot $1 ; \%$ outer chamber radius after burn, in

112. rinr1=rin1f-rs1; \%inner chamber left after burn, in

113. rour1=rou1-rin1f-deltarc1f; \%outer chamber left after burn, in

114.

115. massox $1=\operatorname{mdotox} 1 * t b 1 ; \%$ mass of oxidizer needed, $1 \mathrm{bm}$

116. massf $1=$ rhof* ${ }^{*}{ }^{*} \mathrm{Lc} 1 *\left(\operatorname{rou} 1^{\wedge} 2-\operatorname{rs} 1 \wedge 2-(\operatorname{rin} 1+\operatorname{deltarc} 1)^{\wedge} 2+\operatorname{rin} 1 \wedge 2\right)$; \% mass of fuel grain, $\mathrm{lbm}$

117. Massf $1=\operatorname{rhof}^{*} \mathrm{pi}^{*} \mathrm{Lc} 1 *\left((\operatorname{rin} 1 \mathrm{f}+\operatorname{deltarc} 1 \mathrm{f})^{\wedge} 2-(\operatorname{rin} 1+\operatorname{deltarc} 1)^{\wedge} 2+\operatorname{rin} 11^{\wedge} 2-\operatorname{rin} 1 f^{\wedge} 2\right)$;

$\%$ mass of fuel burned, $1 \mathrm{bm}$

118.

119. rinj1=rin $1+$ deltarc $1 / 2$; \%center radius of injector circle, in

120. rv1=(rin1-rs1)/3+deltarc1/2; \%radius of vortex outlet, in

121. Ninj1 $=2 *$ pi*rinj $1 / \mathrm{rv} 1 ; \%$ number of injector vortices

122.

123. At $1=\mathrm{F} 1 /(\mathrm{Cf} * \mathrm{pc} 1) ; \%$ throat area, $\mathrm{in}^{\wedge} 2$

124. Rt $1=\operatorname{sqrt}(\mathrm{At} 1 / \mathrm{pi}) ; \%$ throat radius, in 
125.

126. Rinj1=sqrt(mdotox $1 /(\mathrm{Cd} 1 * N i n j *$ pi*sqrt $(2 *$ rhoN2O*deltaPinj*g/144)) $)$ \%

injector hole radius, in

127.

128. $\mathrm{A} 10 \mathrm{ex}=\mathrm{A} 2 \mathrm{o}^{*}(\mathrm{~F} 1 / \mathrm{F} 2)^{\wedge} 2 ; \%$ initial port area ratio to check similarity

129. deltarc1ex $=\left(\operatorname{sqrt}\left(\mathrm{A} 10 \mathrm{ex} * \mathrm{pi}+\mathrm{pi}^{\wedge} 2 * \operatorname{rin} 1 \wedge 2\right)-\mathrm{pi} * \mathrm{rin} 1\right) / \mathrm{pi}$

130. tb1ex=tb2*Abar1/Abar2; \%Burn time for complete similarity

131.

132.\%Results

133. disp(['The Major Thrust is: ',num2str(F2),' (lbf)']);

134. disp(['The Major Burn Time is: ',num2str(tb2),' (sec)'])

135. disp(['The Major Chamber Pressure is: ',num2str(pc2),' (psi)'])

136. disp(['The Major Total Impulse is: ',num2str(Itot2),' (lb*sec)'])

137. disp(['The Major Oxidizer Flow Rate is: ',num2str(mdotox2),' (lbm/s)'])

138. disp(['The Major Average Oxidizer Mass Flux is: ',num2str(Gox2),' (lb/in^2/s)'])

139. disp(['The Major Oxidizer Mass Needed is: ',num2str(massox2),' (lbm)'])

140. disp(['The Major Fuel Grain Mass is: ',num2str(massf2),' (lbm)'])

141. disp(['The Major Fuel Burned is: ',num2str(Massf2),' (lbm)'])

142. disp(['The Major Fuel Mass Flux is: ',num2str(Gf2),' (lb/in^2/s)'])

143. disp(['The Major Center Support Radius is: ',num2str(rs2),' (in)'])

144. disp(['The Major Inner Grain Outer Radius is: ',num2str(rin2),' (in)'])

145. disp(['The Major Chamber delta Radius is: ',num2str(deltarc2),' (in)'])

146. disp(['The Major Outer Grain Outer Radius is: ',num2str(rou2),' (in)'])

147. disp(['The Major Chamber Length is: ',num2str(Lc2),' (in)'])

148. disp(['The Major Inner Grain Remaining is: ',num2str(rinr2),' (in)'])

149. disp(['The Major Outer Grain Remaining is: ',num2str(rour2),' (in)'])

150. disp(['The Major Average Chamber Area is: ',num2str(Abar2),' (in^2)'])

151. disp(['The Major Throat Radius is: ',num2str(Rt2),' (in)'])

152. disp(['The Major Injector Ring Radius is: ',num2str(rinj2),' (in)'])

153. disp(['The Major max \# of injector vortexes is: ',num2str(Ninj2)])

154. disp(['The Major Injector Hole Radius is: ',num2str(Rinj2),' (in)'])

155. disp(['The Major Oxidizer Tank Length is: ',num2str(tank12),' (in)'])

156. $\operatorname{disp}('$ ')

157. disp(['The mini Thrust is: ',num2str(F1),' (lbf)']);

158. disp(['The mini Burn Time is: ',num2str(tb1),' (sec)'])

159. $\operatorname{disp}([$ 'The mini Chamber Pressure is: ',num2str(pc1),' (psi)'])

160. disp(['The mini Oxidizer Flow Rate is: ',num2str(mdotox1),' (lbm/s)'])

161. disp(['The mini Average Oxidizer Mass Flux is: ',num2str(Gox1),' (lb/in^2/s)'])

162. disp(['The mini Oxidizer Mass Needed is: ',num2str(massox1),' (lbm)'])

163. disp(['The mini Fuel Grain Mass is: ',num2str(massf1),' (lbm)'])

164. disp(['The mini Fuel Burned is: ',num2str(Massf1),' (lbm)'])

165. disp(['The mini Fuel Mass Flux is: ',num2str(Gf1),' (lb/in^2/s)'])

166. disp(['The mini Center Support Radius is: ',num2str(rs1),' (in)'])

167. disp(['The mini Inner Grain Outer Radius is: ',num2str(rin1),' (in)'])

168. disp(['The mini Inner Grain Outer Radius >= ',num2str(rin1n),' (in)'])

169. disp(['The mini Chamber delta Radius is: ',num2str(deltarc1),' (in)']) 
170. disp(['The mini Outer Grain Outer Radius is: ',num2str(rou1),' (in)'])

171. disp(['The mini Chamber Length is: ',num2str(Lc1),' (in)'])

172. disp(['The mini Inner Grain Remaining is: ',num2str(rinr1),' (in)'])

173. disp(['The mini Outer Grain Remaining is: ',num2str(rour1),' (in)'])

174. disp(['The mini Average Chamber Area is: ',num2str(Abar1),' (in^2)'])

175. disp(['The mini Throat Radius is: ',num2str(Rt1),' (in)'])

176. disp(['The mini Injector Ring Radius is: ',num2str(rinj1),' (in)'])

177. disp(['The mini max \# of injector vortexes is: ',num2str(Ninj1)])

178. disp(['The mini Injector Hole Radius is: ',num2str(Rinj1),' (in)'])

179. $\operatorname{disp}(')$

180. disp(['The rou1 adjustment variable is: ',num2str(Q1),' (in)'])

181. disp(['The rin2 adjustment variable is: ',num2str(q2),' (in)'])

182. disp(['The rou2 adjustment variable is: ',num2str(Q2),' (in)'])

183. disp(['The Major fuel linear regression rate is: ',num2str(rdot2),' (in/s)'])

184. disp(['The mini rdot used is: ',num2str(rdot1),' (in/s)'])

185. disp(['The mini rdot should be is: ',num2str(rdotex1),' (in/s)'])

186. disp(['The mini burn time should be: ',num2str(tb1ex),' (s)'])

187. disp(['The mini delta r should be: ',num2str(deltarclex),' (in)'])

188. disp(['The Factor of Safety, for burn parameters on inner grain is: ',num2str(FMi)])

189. disp(['The Factor of Safety, for burn parameters on outer grai is: ',num2str(FMo)])

190. disp(['The nitrous tank radius is: ',num2str(tankr2),' (in)'])

191. disp(['The \# of Injector holes is: ',num2str(Ninj)])

192. disp(['The Flow coefficient for Major injectors is: ',num2str(Cd2)])

193. disp(['The Flow coefficient for mini injectors is: ',num2str(Cd1),' (in)'])

194. disp(['The mini chamber pressure is: ',num2str(pc1),' (psi)'])

195. disp(['The Major chamber pressure is: ',num2str(pc2),' (psi)'])

196. disp(['The dP over injector is: ',num2str(deltaPinj),' (psi)'])

197. disp(['The thrust coefficient is: ',num2str(Cf),' (in)'])

198. disp(['The Pressure at Design Altitude(7000 ft) is: ',num2str(P3),' (psi)'])

199. disp(['The expected Specific Impulse is: ',num2str(Isp),' (s)'])

200. disp(['The Oxidizer to Fuel Ratio is: ',num2str(OF)])

201. disp(['The fuel density is: ',num2str(rhof),' (lb/in^3)'])

202. disp(['The liquid N2O density is: ',num2str(rhoN2O),' (lb/ft^3)']) 